\title{
Review of research on loosening of threaded fasteners
}

\author{
Hao GONG, Xiaoyu DING, Jianhua LIU*, Huihua FENG \\ School of Mechanical Engineering, Beijing Institute of Technology, Beijing 100081, China \\ Received: 09 August 2020 / Revised: 16 January 2021 / Accepted: 25 January 2021 \\ (C) The author(s) 2021.
}

\begin{abstract}
Loosening of threaded fasteners is a key failure mode, which is mainly caused by the slippage and friction behaviors on the thread and bearing surfaces, and will affect the integrity and reliability of products. Numerous scholars have conducted research on the loosening of threaded fasteners; however, comprehensive reviews on the loosening of threaded fasteners have been scarce. In this review article, we define loosening as a loss of preload and divide it into non-rotational and rotational loosening. The causes and mechanisms of non-rotational and rotational loosening are summarised. Some essential topics regarding loosening under transverse vibration have also attracted significant attention and have been investigated widely, including the loosening curve, critical condition of loosening, and influencing factors of loosening. The research carried out on these three topics is also summarised in this review. It is believed that our work will not only help new researchers quickly understand the state-of-the-art research on loosening, but also increase the knowledge of engineers on this critical subject. In the future, it is important to conduct more quantitative research on local slippage accumulation, and the relationship between local slippage accumulation and rotational loosening, which will have the potential to comprehensively unravel the loosening mechanism, and effectively guide the anti-loosening design of threaded fasteners.
\end{abstract}

Keywords: threaded fasteners; loosening; vibration; loosening curve; critical condition; influencing factors

\section{Introduction}

Threaded fasteners, with the reputation of "industrial rice" are standard fundamental components in the industry, providing the functions of connecting, fastening, and sealing [1,2]. They are applied widely in mechanical, aerospace, civil, and marine engineering, among others, owing to their low cost, good interchangeability, and ease of installation and disassembly. Although threaded fasteners are usually small and even inconspicuous, they play a significant role in guaranteeing structural integrity and reliability in service.

Loosening is a key issue facing the threaded fasteners. In engineering applications, threaded fasteners may be exposed to severe work-environments and are subjected to periodic external loadings, which may induce the risk of loosening. Loosening is mainly caused by the slippage and friction behaviors on the thread and bearing surfaces. It results in the loss of the intrinsic functions of threaded fasteners and affects the reliability of products. A survey of automobile dealer service managers in the US indicated that $23 \%$ of the service problems could be attributed to the loosening of fasteners, and as many as $12 \%$ of all new cars were found to have loose fasteners [3]. Occasional loosening might cause a fateful consequence. Figure 1(a) shows a railway accident caused by a high-speed train derailment in the United Kingdom in 2007 [4]. This accident resulted from nuts detaching from their bolts owing to loosening and allowing the switch rail to be struck by the inner faces of the passing train wheels. In 2010, an accident resulting from a collapse at Space Lost, an amusement park in eastern Shenzhen,

* Corresponding author: Jianhua LIU, E-mail: jeffliu@bit.edu.cn 
(a)

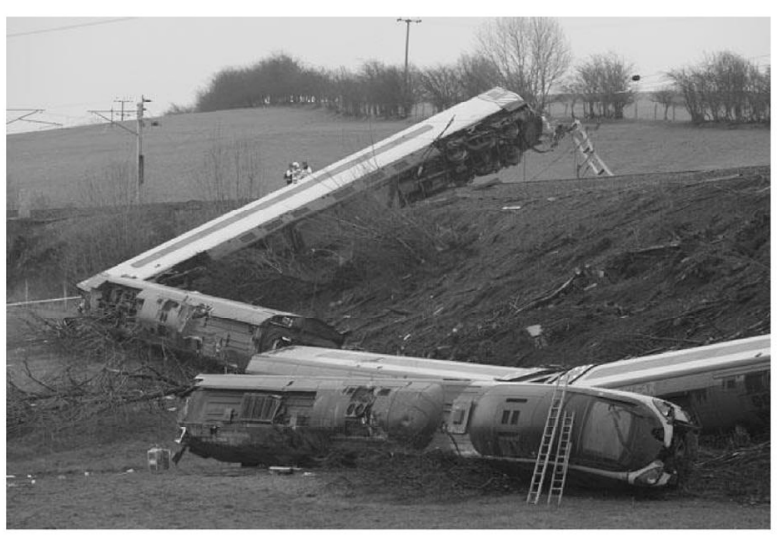

(b)

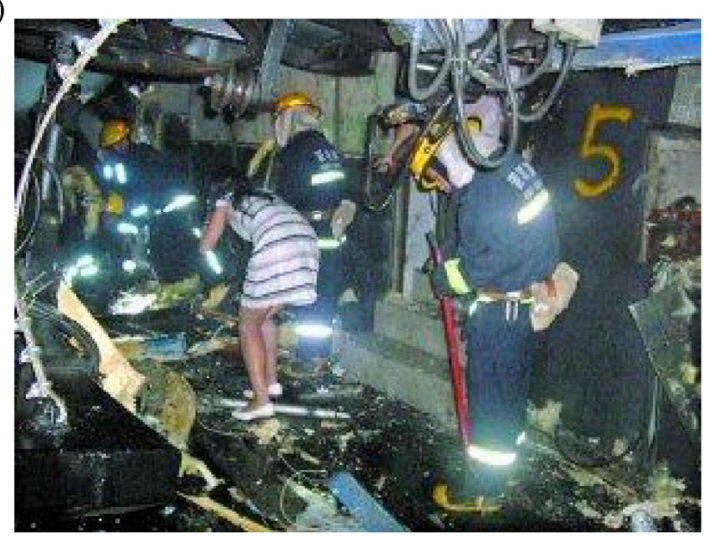

Fig. 1 Two severe accidents caused by loosening of threaded fasteners: (a) a high-speed train derailment, 2007, UK; (b) an accident at the Space Lost amusement park, 2010, China.

China occurred as shown in Fig. 1(b), causing six deaths and injuries to 10 people [5]. The main reason was loosening, which triggered the fatigue fracture of a bolt. Therefore, loosening failure is an important factor that influences the reliability and safety of products.

Loosening, in a strict sense, can be defined as the rotation process of internal and external threads in a direction opposite to the tightening direction; that is, a reverse rotation appears and causes a decrease in the preload. This is also called "self-loosening" [6]. The magnitude of the reverse rotation angle can be an indicator of the loosening severity. Engineering experience and scientific research have shown that the retention of preload during service is the key to maintaining the functions of threaded fasteners and ensuring structural integrity and reliability. However, the preload in threaded fasteners may decrease even without a reverse rotation because of effect of plastic deformation, creep, wear, etc., as shown in next chapter [7]. Therefore, in this review, we have adopted a broader definition, that is, loosening corresponding to a loss of preload. The decay rate of preload is an important parameter to quantify the loosening severity. According to this definition, loosening can be classified into two categories: non-rotational loosening and rotational loosening. The former indicates that the preload decreases slowly without a reverse rotation between the internal and external threads, while the latter indicates that the preload decreases rapidly owing to the reverse rotation against the tightening direction.
Over the past 80 years, the topic of loosening of fasteners has attracted significant attention, and many scholars have conducted numerous studies on the loosening of threaded fasteners. Thus, different ways of understanding the loosening process have been developed. Although a few researchers did review the existing work on loosening $[8,9]$, these reviews were incomplete. In addition, the various issues involved were not addressed in a systematic manner. Therefore, a comprehensive review on the loosening of threaded fasteners is still lacking, which is the motivation of this study. Here, we have extensively reviewed the literature on loosening published over the past 80 years, summarised them systematically, and developed this review article. We believe that our work will not only help new researchers quickly understand the current research status on the loosening of threaded fasteners, but also increase the knowledge of the engineers on this subject, and guide them in choosing proper anti-loosening structures in engineering applications.

Throughout the literature on loosening, researchers have attempted to clarify the causes for loosening and reveal the underlying mechanism. Some topics regarding loosening under transverse vibration have also been investigated widely, including the loosening curve, critical condition of loosening, and influencing factors of loosening. The framework of this review article is shown in Fig. 2. Firstly, the available research on the cause and mechanism of loosening is reviewed from the aspects of non-rotational and rotational loosening. Subsequently, the research status 


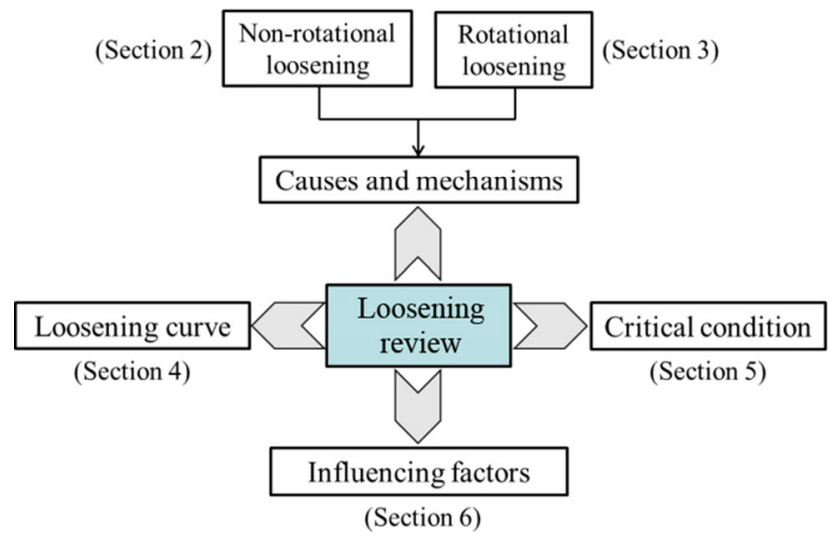

Fig. 2 Framework of the review.

of loosening curve, critical condition of loosening, and influencing factors of loosening under transversal vibration is systematically summarised. Finally, some perspectives and future research directions for loosening are outlined.

\section{Causes and mechanisms of non-rotational loosening}

Non-rotational loosening implies that the preload in threaded fasteners is decreased even without a rotation of the internal and external threads against the tightening direction. The causes for this phenomenon comprise, but are not limited to, embedding loss, fretting wear, stress redistribution of the contact interface, creep, stress relaxation, and cyclic plastic deformation of bolts or nuts. The corresponding mechanisms and progression of non-rotational loosening are summarised in Table 1.

Embedding loss: Contact interfaces, including the thread, joint, and bearing surfaces are usually not perfect owing to the surface morphology. There can be numerous protrusions, as shown in Fig. 3. Under an external loading, these protrusions are easily pressurised and deformed plastically. Over time, surfaces may be flattened and cannot recover even if the external loading is removed, which results in a preload loss. This phenomenon is called the embedding loss. As early as 1972, Meyer and Strelow [10] found that approximately $80 \%$ of this type of preload loss takes place when a bolted joint is first loaded, while the remaining $20 \%$ is caused by further loading. The German national standard VDI 2230 [11] highlights that the amount of embedding loss increases with the clamping length ratio; however, it is nearly independent of the number and surface roughness of the contact interfaces. Therefore, a short grip length should be avoided (i.e., clamping length ratio should be larger than 3 ). The equation for the embedding loss is given in VDI 2230. Recently, Denkert et al. [12] experimentally found that the embedding loss caused by a clamping length ratio of 1 appeared to have an insignificant difference from that caused by a clamping length ratio of 4 , and questioned the calculation equation in VDI 2230. The embedding loss and its accurate equation require further research in the future. For convenience, the embedding loss can be approximated as $10 \%$ of the preload in practical applications [7].

Table 1 Summary of causes, mechanisms, and progressions of non-rotational loosening.

\begin{tabular}{|c|c|c|}
\hline Cause & Mechanism & Progression \\
\hline Embedding loss & $\begin{array}{l}\text { Protruding points on a contact surface are plastically } \\
\text { deformed. }\end{array}$ & $\begin{array}{l}\text { Accounts for approximately } 10 \% \text { of the initial preload; } 80 \% \\
\text { of the embedding loss appears after the first loading, while } \\
\text { the remaining } 20 \% \text { is caused by further loading. }\end{array}$ \\
\hline Creep & $\begin{array}{l}\text { Chronic plastic strain accumulates over time owing } \\
\text { to a constant stress. }\end{array}$ & $\begin{array}{l}\text { The softer the gasket and coating are, the larger the preload } \\
\text { loss caused by creep. }\end{array}$ \\
\hline Stress relaxation & $\begin{array}{l}\text { Stress decreases through time while strain remains } \\
\text { unchanged. }\end{array}$ & High temperature accelerates the stress relaxation loss. \\
\hline $\begin{array}{l}\text { Cyclic plastic } \\
\text { deformation }\end{array}$ & $\begin{array}{l}\text { Cyclic external force makes local stress exceed the } \\
\text { yield point. }\end{array}$ & $\begin{array}{l}\text { Ranges from } 10 \% \text { to } 40 \% \text { of the initial preload within } 200 \\
\text { loading cycles, and then its effects on loosening will vanish. }\end{array}$ \\
\hline $\begin{array}{l}\text { Stress redistri- } \\
\text { bution }\end{array}$ & $\begin{array}{l}\text { Friction behaviour of thread surface is irreversible } \\
\text { under shear force. }\end{array}$ & $\begin{array}{l}\text { Accounts for approximately } 5 \% \text { of the initial preload; the } \\
\text { preload loss and duration are affected by the transverse force. }\end{array}$ \\
\hline Fretting wear & $\begin{array}{l}\text { Repeated micro-slips cause wearing of surface } \\
\text { materials. }\end{array}$ & $\begin{array}{l}\text { Fretting wear changes the distribution and magnitude of } \\
\text { contact stress; preload loss is not constant. }\end{array}$ \\
\hline
\end{tabular}




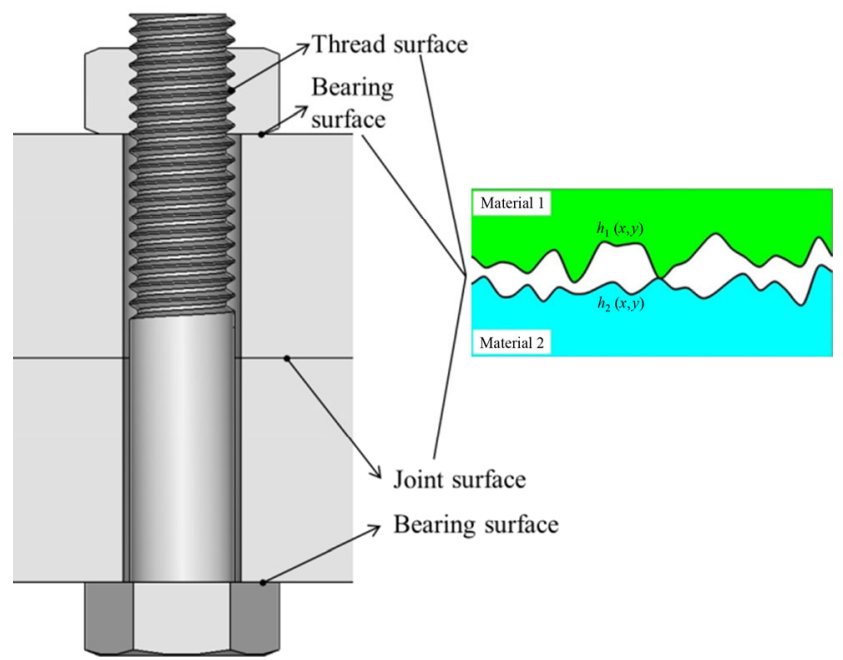

Fig. 3 Contact interface and actual surface profile in a bolted joint.

Creep: Creep is the phenomenon of plastic strain accumulation owing to a constant stress. This is the result of long-term exposure to high levels of stress that is still below the yield strength of the material. Creep will cause a chronic preload loss. This type of preload loss should be a comprehensive outcome of the creep of bolts, clamped joints, gaskets, and coatings in bolted joints [13]. For a high-strength bolted joint with a hardened washer and without coating, it was found that the preload loss caused by creep ranged from $3 \%$ to $5 \%$ of the initial preload, after the bolted joint was tightened [14]. However, gaskets made of soft materials and used in bolted joints for sealing may exhibit a severe creep behaviour, and lead to a large preload loss. Abboud and Nassar [15] used an MTS10 machine for the creep test, where a relatively soft gasket was compressed between two stiff steel plates to a predetermined uniform stress level. Their experimental results indicated that for two different thicknesses, polytetrafluoroethylene (PTFE) gaskets showed respective drops of $7 \%$ and $20 \%$ of the initial preload, while red rubber gaskets exhibited respective drops of $55 \%$ and $65 \%$ of the initial preload. In addition, coatings, such as zine applied to protect steel fasteners from corrosion could also result in a large preload loss caused by creep. Yang et al. [16] found that a loss of $20 \%$ of the initial preload occurred owing to the coating creep. In summary, soft gaskets and coatings may result in a comparatively severe creep behaviour and dominate the preload loss, and should be considered carefully in engineering applications.

Stress relaxation: Stress relaxation can also cause a long-term preload loss, such as creep. However, stress relaxation implies that the stress decreases over time, while the strain remains unchanged. At the ambient temperature, the stress relaxation loss is relatively small. It was found that in a high-tension bolted joint with a stainless-steel plate, the stress decrease in the bolt was no more than $2 \%$ [17] and the preload was almost unchanged. However, high temperatures will accelerate this type of preload loss. Guo et al. [18] performed stress relaxation tests on 1Cr10NiMoW2VNbN steel using a CSS-3900 creep testing machine at $600{ }^{\circ} \mathrm{C}$ with initial stresses of 266, 300 , and $350 \mathrm{MPa}$ for 1,000 h. A large decrease in the stress was found, which was more than $50 \%$ of the initial stress. Apparently, the preload loss was severe. Therefore, high temperature is a key factor influencing the preload loos caused by stress relaxation, and the standardised test method for the quantification of stress relaxation should be applied at a specific temperature and time [19].

Cyclic plastic deformation: Under cyclic external loading, the local stress in threaded fasteners may exceed the yield point, triggering cyclic plastic deformation, which causes a decrease in and redistribution of local stress, thereby resulting in a preload loss. Jiang et al. [20] applied a homemade Junker test apparatus to generate cyclic transversal vibration to a threaded fastener, whose nut was glued to the bolt using a strong thread locker. It was experimentally observed that the preload loss ranged from $10 \%$ to $40 \%$ of the initial preload within 200 loading cycles. After 200 vibration cycles, the preload remained almost unchanged. Then they built a finite element (FE) model of a bolted joint without a thread lead angle to reveal that the local cyclic plasticity occurring near the roots of the engaged threads resulted in a cyclic strain ratcheting and caused a preload loss. Subsequently, Hou and Liao [21] further investigated the effects of various factors on the loss of preload caused by cyclic plasticity deformation. The FE model of the bolted joint also had no thread lead angle. It was found that the magnitude of the transverse force had the most significant effect on the preload loss caused by cyclic plasticity deformation, which was 
also verified by other researchers [22]. In addition, these researchers also demonstrated that the preload loss by cyclic plastic deformation would soon end after a specific number vibration cycles.

Stress redistribution: This is a recently proposed cause for the preload loss. Gong et al. [22] built an elastic finite element model of a bolted joint without a thread lead angle and applied a cyclic transverse force; however, a loss of approximately $5 \%$ of the initial preload was still observed. It was found that the contact stress on the thread surface changed to a sinusoidal distribution from the initial uniform distribution after a complete vibration cycle. The integral of the contact stress is equivalent to the preload. The results indicated that the integral of the contact stress with a sinusoidal distribution was smaller than that with a uniform distribution, which implied a loosening behaviour. It also showed that the stress redistribution was generally achieved after a specific number of vibration cycles. Subsequently, Gong et al. [23] further researched the effects of various factors on the preload loss, caused by stress redistribution. It was found that the larger the transverse force, the more serious the preload loss, and the shorter the duration of the stress redistribution.

Fretting wear: The threaded surface is generally uneven owing to the surface morphology, as shown in Fig. 3. After the preload is applied, the external and internal threads are not in complete contact with each other. The protruding points may be embedded into the concave space. Under a cyclic external force, repeated micro-slips occur at some local protruding points, resulting in the surface material wearing gradually and preload being decreased [24]. Liu et al. $[25,26]$ clamped two testing fixtures using a bolt and a nut. The bolt was made of a low-carbon steel and coated with zinc to protect it from rust. One fixture was fixed at one end and an axial excitation was applied at the end of the other fixture to investigate the fretting wear behaviour of the threaded surface under cyclic axial loadings. Zhou et al. [27] and Zhang et al. $[28,29]$ applied an electro-hydraulic servo fatigue testing machine to investigate the fretting wear behaviour of a threaded surface under cyclic transverse loadings. The upper fixture was connected to the grip of the fatigue testing machine, while the lower fixture was fixed to the test stand. The upper and lower fixtures were made of 1045 steel and clamped using a bolt and nut. The fretting wear profiles and their changes were clearly observed and measured using scanning electron microscopy (SEM). It was found that fretting wear changed the distribution and magnitude of the contact stress on the threaded surface; thus, the preload decreased with an increase in the number of vibration cycles. After a certain number of vibration cycles, the fretting wear did not continue. The preload losses caused by fretting wear for different bolted joints were not constant; they were influenced by factors, such as the magnitude of preload, amplitude of the axial or transverse loadings, and coating type.

From the above summaries, we can conclude that when no external loading is applied, embedding loss, creep, and stress relaxation dominate the preload loss, which are all long-term loss behaviours. Among these three causes, creep results in a larger preload loss if a soft gasket and coating are employed, while stress relaxation causes a larger preload loss if the working temperature is high. In contrast, when an external loading is employed cyclically to threaded fasteners, cyclic plastic deformation, stress redistribution, and fretting wear dominate the preload loss. The preload does not always continue and end after a certain number of vibrational cycles. Usually, the preload loss resulting from the above six causes is unavoidable. In practical applications, the addition of a tightening torque to offset the potential preload loss is typically employed as a solution.

\section{Causes and mechanisms of rotational loosening}

Under an external loading, the frictional forces between the internal and external threads may be overcome, and a reverse rotation against the tightening direction could occur. Compared with the non-rotational loosening, this type of loosening modality can induce a continuous preload loss until the bolt fractures or the preload vanishes, resulting in a greater harm. In fact, loosening accidents frequently begin with a rotational loosening. Therefore, rotational loosening is the main focus of loosening research over the years, and some theories have been proposed to explain the 
rotational loosening process and reveal its mechanism. The causes initiating a rotational loosening include axial, transverse, torsional, and bending vibration loadings, as well as impact loading, as shown in Fig. 4. Here, we provide a systematic summary of the research work on the rotational loosening caused by different external loadings.

\subsection{Axial vibration loading}

Axial vibration loading refers to the vibration parallel to the bolt or nut axis. Whether axial vibration is capable of causing rotational loosening has always been controversial. Research on the effect of axial vibration on rotational loosening dates back to the 1940s and can be divided into two periods, based on the research methods used, as listed in Table 2. The first period ranges from the 1940s to the late 1970s when experimental methods were mainly applied to test the rotational loosening behaviour caused by axial vibration loading. The second period ranges from 1996 to the present when researchers mainly employed a finite element analysis (FEA) or theoretical analyses to demonstrate how axial vibration loading resulted in rotational loosening; here, experiments were conducted only for validation of the analytical or numerical results.

Period I: Goodier and Sweeney [30] from Cornell University were probably the first to investigate rotational loosening under an axial vibration loading in 1945. In their experiment, microscopes were used to measure small nut rotation on a bolt. After 500 cycles, a revolution of $0.0055 \mathrm{Rad}$ was observed, which

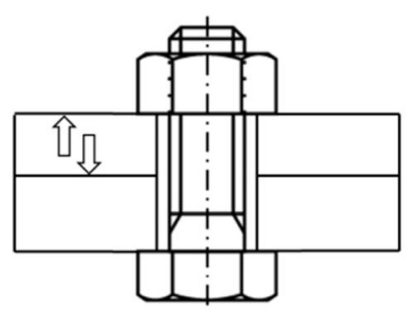

(a) Axial vibration

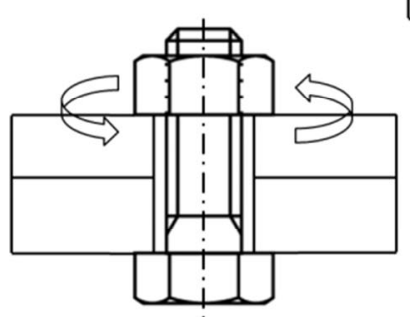

(c) Torsional vibration
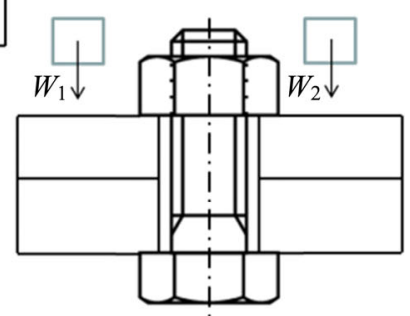

(e) Impact

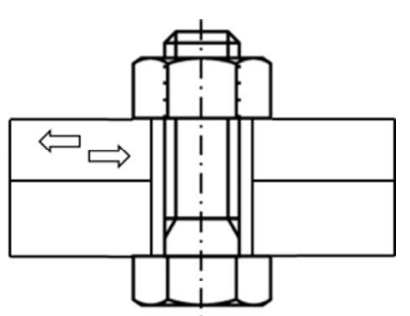

(b) Transversal vibration

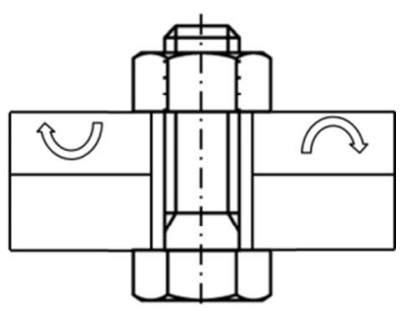

(d) Bending vibration

Fig. 4 Schematic diagram of various external loadings resulting in rotational loosening.

Table 2 Summary of research on rotational loosening caused by axial vibration loading.

\begin{tabular}{|c|c|c|c|c|}
\hline Stages & Method & Ref. & Occurrence & Progress \\
\hline \multirow{2}{*}{$\begin{array}{l}\text { Period I: } \\
1940 \text { s to late } \\
1970 \text { s }\end{array}$} & \multirow[b]{2}{*}{ Experiment } & {$[32]$} & Yes & Proposed elastic radial expansion theory. \\
\hline & & {$[36]$} & No & $\begin{array}{l}\text { Conducted a novel axial vibration experiment, challenging the } \\
\text { findings in Ref. [32]. }\end{array}$ \\
\hline \multirow{3}{*}{$\begin{array}{l}\text { Period II: } \\
1996 \text { to the } \\
\text { present }\end{array}$} & \multirow{3}{*}{$\begin{array}{l}\text { FEA or } \\
\text { theoretical } \\
\text { analysis }\end{array}$} & {$[39-43]$} & Yes & $\begin{array}{l}\text { Found that loosening, tightening, or no twist could occur in a } \\
\text { cap screw subjected to axial vibration. }\end{array}$ \\
\hline & & {$[44]$} & Yes & $\begin{array}{l}\text { Clarified that the relative rotation was enhanced in the loading } \\
\text { process and inhibited in the unloading process. }\end{array}$ \\
\hline & & {$[26-28,46,47]$} & No & $\begin{array}{l}\text { Found that the initial preload loss was caused by plastic } \\
\text { deformation, fretting wear or others. }\end{array}$ \\
\hline
\end{tabular}


corresponded to a loss of approximately $73 \%$ in the preload. Then, a simple theory was proposed to explain the rotational loosening caused by the axial vibration loading. The theory surmised that under an axial vibration, the elastic radial expansion of the nut diameter and the elastic contraction of the bolt diameter were governed by the Poisson ratio of the material. This radial deformation would result in a circumferential movement owing to the helix angle, which accumulated with an increasing number of vibration cycles, and finally caused a large rotational loosening. However, Goodier and Sweeney's experiment was quasi-static, which did not agree with the practice. Therefore, some researchers improved the original experimental setting by applying a dynamic axial loading and examined the effects of various factors on rotational loosening. For example, Sauer et al. (1950) [31] analysed the influences of number of vibration cycles, dynamic to static load ratio, contact surface condition, and misalignment on rotational loosening. Paland (1966) [32] tested various types of threaded fasteners subjected to axial loadings and arithmetically determined the rule of loosening by measuring the tangential strain on the surface of the nut. Gambrell (1968) [33] examined how loosening was affected by the bolt thread series (coarse or fine), initial preload, lubrication, dynamic to static load ratio, frequency of loading, and number of cycles.

Meanwhile, the above rotational loosening theory was also challenged during this stage. In 1964, Hongo [34] measured the relative rotation between a bolt and nut by observing the oscillation of a beam of light projected onto a mirror pasted on the bolt in his experiment. The results showed that there was no continuous rotation between the bolt and nut in the loosening direction. Therefore, he disagreed with the conclusion of Goodier and Sweeny [30] that the bolt and nut underwent relative rotation in the direction that would loosen the fastener, as long as there was a variation in the axial tensile force of the bolt. In 1979, Sakai [35] experimentally found that in the initial vibration cycles (approximately 200 cycles), the preload loss occurred mainly owing to plastic deformation. In the following cycles, if the amplitude of the axial vibration was not large, the preload remained unchanged (i.e., rotational loosening did not occur).

Period II: Since Junker [36] found large-scale loosening under transversal vibration in an experiment in 1969, a few researchers have, subsequently, focused on the rotational loosening by axial vibration loading. Until 1996, Hess and his co-workers [37] continued to conduct research on rotational loosening caused by axial vibration loading. They initially performed a kinematic analysis for the twisting of a cap screw in a tapped hole, loaded by gravity (without preload) and subjected to axial harmonic vibration. It was shown theoretically that three types of motion could occur: twist up, twist down, and no twist. In another study, Hess and Davis [38] designed a test apparatus consisting of a block, into which a threaded component was inserted, and a shaker. The shaker provided an axial excitation. The axial motions of both the base and cap screw were measured with miniature accelerometers and recorded with a multi-channel dynamic signal analyser. The experimental results agreed with the theoretical results. Then, an improved dynamic model [39] loaded by gravity and a slight preload $(<100 \mathrm{~N})[40,41]$ was analysed. This indicates that loosening, tightening, or no twist might occur in the cap screw subjected to axial vibration, which is mainly governed by the amplitude and frequency of axial vibration. Additionally, the preload would be unchanged after a certain number of cycles, either in loosening or tightening [41]. These studies provided significant insight into the mechanism of rotational loosening for threaded fasteners subjected to cyclic axial vibration. However, in practice, the preload in a threaded fastener is far greater than $100 \mathrm{~N}$. Therefore, the above theoretical model, mathematical analysis, and corresponding conclusion must be further verified under practical preloads.

Furthermore, for a threaded fastener loaded by a practical preload, the rotational loosening behaviour caused by an axial vibration was also investigated by some researchers using FEA and theoretical analyses. Izumi and Take [42] (2007) clarified the loosening mechanism by three-dimensional FEA and found that the rotational loosening was enhanced during the loading process, while it was inhibited during the unloading process, and that loosening was caused by the slippage at the bearing surface induced by nut deformation. The theoretical analysis of Sakai [43] (2011) agreed with the above finding, that is, the evolution of relative rotation in the loading and 
unloading processes was different. Moreover, the critical condition for rotational loosening by axial vibration was formulated, which explained why rotational loosening rarely occurred in an actual use.

Subsequently, some researchers provided more evidence to demonstrate that axial vibration hardly resulted in rotational loosening, by analysing the preload decline induced by an axial vibration. They found that the initial preload loss was caused by plastic deformation $[44,45]$, fretting wear $[25,26]$ or other factors. After that, the preload did not change with an increase in the number of vibration cycles, which indicated no rotational loosening. In addition, the authors also established an elastic finite element model of a threaded fastener with an ideal contact interface and applied cyclic axial vibration. It was also found that the preload remained almost constant, which meant no rotational loosening. From the above research, we can see that a slight rotational loosening caused by axial vibration was observed in the early days when the measuring accuracy may not be sufficiently high. Therefore, we speculate that the rotational loosening and loosening angle under axial vibration observed in the early research work, were probably owing to plastic deformation and measuring errors.

\subsection{Transverse vibration loading}

Transverse vibration loading refers to the vibrations perpendicular to the bolt or nut axis. It was demonstrated that transverse vibrations could result in a large-scale rotational loosening; this attracted much attention in earlier research work. Rotational loosening was attributed to slippage behaviour between the contact interfaces [46]. According to the difference in the slippage modes, two typical theories, i.e., complete slippage and local slippage accumulation theories were proposed to explain the rotational loosening process caused by a transverse vibration. In the following subsection, we will systematically summarise the relevant research work from both these perspectives in a chronological order, as shown in Table 3.

\subsubsection{Complete slippage theory}

In 1969, a German engineer named Junker [36] designed an experimental apparatus, by which a cyclic transverse vibration was applied to threaded fasteners for the first time. The Junker test apparatus consisted of a fixed base, moving plate, and several sensors monitoring the preload, shear load, and transverse displacement, as shown in Fig. 5. A shear load was applied to the joint through a transverse movement of the plate between the nut and bolt. The transverse movement was generated by an eccentric structure. Experimental results showed that evident rotational loosening and large preload loss occurred under a cyclic transverse vibration. He proposed what is now a widely cited theory to explain the rotational loosening of fasteners under a transverse vibration loading. This can be illustrated using a block on an incline system, as shown in Fig. 6. Here, the frictional force between the block and the incline is sufficient to prevent the block from sliding down the incline in the absence of any external vibration loading (see Fig. 6(a)). When the block is subjected to a transverse vibration, large enough to overcome the frictional force between the block and the incline, the block not only slips in the transverse direction, but also down the incline (see Fig. 6(b)). In Junker's theory, the entire internal thread of a nut is assumed to be the block while the complete external thread of the bolt is assumed to be the inclined surface. Therefore, the classical theory indicates that rotational loosening occurs when the frictional forces on a threaded surface are overcome completely, which is the so-called complete slippage theory.

Junker's theory regards the external and internal threads in their entirety. The rotational loosening under a transverse vibration can be explained simply by using Coulomb's friction law. Junker's theory is easy to understand and hence, is widely popular. However, the detailed rotational loosening process under a transverse vibration is still not clearly understood. Subsequently, many researchers have tried to clarify the inherent mechanism of rotational loosening based on the complete slippage theory.

In 1977, Yamamoto and Kasei [47] proposed a rotational loosening process with two different stages. In the first stage, a bolt thread was inclined in a mating nut thread with slippage on the surface of the nut thread, producing an elastic torsion of the bolt shank. In the next stage, the washer face of the nut slipped on the surface of the vibrating plate, 
Table 3 Summary of research on rotational loosening caused by transverse vibration loading.

\begin{tabular}{|c|c|c|c|c|}
\hline Slippage mode & Year & Ref. & Method & Contribution \\
\hline \multirow{8}{*}{$\begin{array}{l}\text { Complete slippage } \\
\text { theory }\end{array}$} & 1969 & Junker [36] & Experiment & $\begin{array}{l}\text { Proposed complete slippage theory; found that transverse vibration } \\
\text { was more likely to induce loosening than other forms of vibration; } \\
\text { invented a transverse vibration apparatus. }\end{array}$ \\
\hline & 1977 & $\begin{array}{l}\text { Yamamoto and } \\
\text { Kasei [47] }\end{array}$ & $\begin{array}{l}\text { Theoretical } \\
\text { analysis }\end{array}$ & $\begin{array}{l}\text { Proposed the rotational loosening process with two different } \\
\text { stages. }\end{array}$ \\
\hline & 1978 & Sakai [48] & $\begin{array}{l}\text { Theoretical } \\
\text { analysis }\end{array}$ & $\begin{array}{l}\text { Analysed the frictional condition indicating the rotational } \\
\text { loosening. }\end{array}$ \\
\hline & 1982 & Tanaka et al. [49] & FEA & $\begin{array}{l}\text { Discussed the relationship between the axial tension and external } \\
\text { loading by applying a numerical method to calculate the stress } \\
\text { distribution on a threaded surface. }\end{array}$ \\
\hline & 1984 & $\begin{array}{l}\text { Yamamoto and } \\
\text { Kasei [50] }\end{array}$ & $\begin{array}{l}\text { Theoretical } \\
\text { analysis }\end{array}$ & $\begin{array}{l}\text { Explained the mechanism of rotational loosening caused by } \\
\text { transverse vibration loading in terms of accumulation and release } \\
\text { of potential energy owing to torsional bolt deformation. }\end{array}$ \\
\hline & 1988 & Kasei et al. [51] & $\begin{array}{l}\text { Theoretical } \\
\text { analysis }\end{array}$ & $\begin{array}{l}\text { Found that rotational loosening on a threaded surface could occur } \\
\text { even when a macroscopic slide was absent on the bearing surface. }\end{array}$ \\
\hline & 1989 & $\begin{array}{l}\text { Vinogradov } \\
\text { and Huang [52] }\end{array}$ & $\begin{array}{l}\text { Theoretical } \\
\text { analysis }\end{array}$ & $\begin{array}{l}\text { Developed a dynamic model of a bolted joint to study rotational } \\
\text { loosening. }\end{array}$ \\
\hline & 1977 & Zadoks et al. [53] & $\begin{array}{l}\text { Theoretical } \\
\text { analysis }\end{array}$ & $\begin{array}{l}\text { Found that the impact between a clamped mass and the clamping } \\
\text { bolt was the main cause of rotational loosening. }\end{array}$ \\
\hline \multirow{10}{*}{$\begin{array}{l}\text { Local slippage } \\
\text { accumulation } \\
\text { theory }\end{array}$} & 2002 & $\begin{array}{l}\text { Pai and Hess } \\
{[56,57]}\end{array}$ & $\begin{array}{l}\text { FEA-1; } \\
\text { Experiment }\end{array}$ & $\begin{array}{l}\text { Proposed that local slippage on contact interfaces contributed to } \\
\text { loosening, instead of complete slippage; found that loosening } \\
\text { occurred before the bearing surface slipped completely. }\end{array}$ \\
\hline & 2005 & Izumi et al. [58] & FEA-1 & $\begin{array}{l}\text { Found that rotational loosening was initiated when the thread } \\
\text { surface reached a complete slip state. }\end{array}$ \\
\hline & 2007 & Izumi et al. [59] & FEA-1 & $\begin{array}{l}\text { Introduced the micro-slip and found that rotational loosening could } \\
\text { proceed when either a micro-slip or complete slip occurred. }\end{array}$ \\
\hline & 2007 & Kasei [60] & $\begin{array}{l}\text { Theoretical } \\
\text { analysis }\end{array}$ & $\begin{array}{l}\text { Presented a theoretical explanation for how rotational loosening } \\
\text { occurred and grew larger. }\end{array}$ \\
\hline & 2007 & Zhang et al. [61] & FEA-2 & $\begin{array}{l}\text { Found that both the micro-slippage on a threaded surface and } \\
\text { cyclic change of pressure on the threaded surface caused by } \\
\text { repeated bending torque initiated rotational loosening. }\end{array}$ \\
\hline & 2010 & $\begin{array}{l}\text { Yokoyama et al. } \\
{[62]}\end{array}$ & $\begin{array}{l}\text { Theoretical } \\
\text { analysis }\end{array}$ & $\begin{array}{l}\text { Found that the inclination of a bolt affected the reaction moment } \\
\text { during the local slippage on a threaded surface, and eventually } \\
\text { caused rotational loosening. }\end{array}$ \\
\hline & 2011 & $\begin{array}{l}\text { Dinger and } \\
\text { Friedrich [63] }\end{array}$ & FEA-2 & $\begin{array}{l}\text { Introduced a parameter, i.e., the ratio of the slip to the total contact } \\
\text { area, to quantify rotational loosening. }\end{array}$ \\
\hline & 2016 & Dinger et al. [64] & FEA-2 & $\begin{array}{l}\text { Obtained the critical condition for loosening in a bolted joint } \\
\text { subjected to torsional and transverse vibration loadings. }\end{array}$ \\
\hline & 2017 & Chen et al. [65] & FEA-2 & $\begin{array}{l}\text { Revealed that the phenomenon of creep slip existed on a contact } \\
\text { surface. }\end{array}$ \\
\hline & 2020 & Gong et al. [66] & $\begin{array}{l}\text { Theoretical } \\
\text { analysis }\end{array}$ & $\begin{array}{l}\text { Found that the cyclic component force along the radial direction } \\
\text { dominated the local slippage accumulation of a threaded surface. }\end{array}$ \\
\hline
\end{tabular}

FEA-1: The finite element model of a bolted joint with a lead angle; the bottom plate is ignored.

FEA-2: The finite element model of a bolted joint with a lead angle; the upper and bottom plates are both built.

accompanied by the loosening rotation of the nut, caused by the spring back of the elastic torsion of the bolt shank. In 1978, Sakai [48] analysed the necessary condition for rotational loosening by considering the straight slippage on a threaded surface and arc slippage on a bearing surface. It was also found that the slippage of the bearing surface was a necessary condition for rotational loosening, and the theoretical 


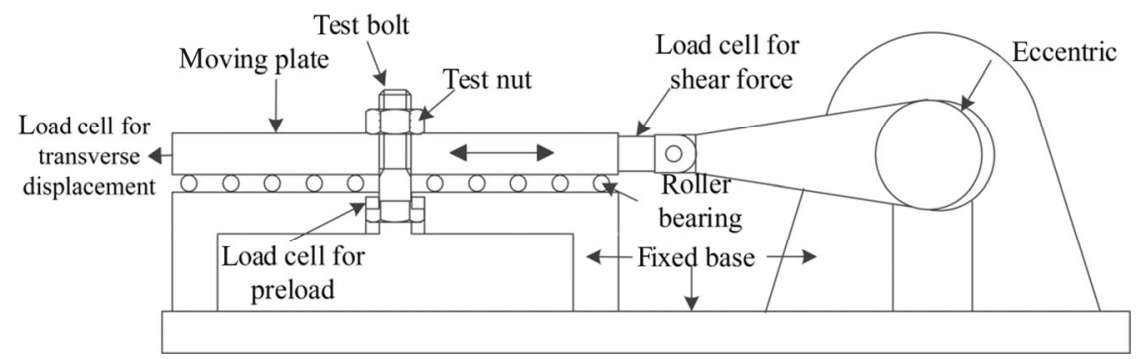

Fig. 5 Schematic of the Junker test apparatus.
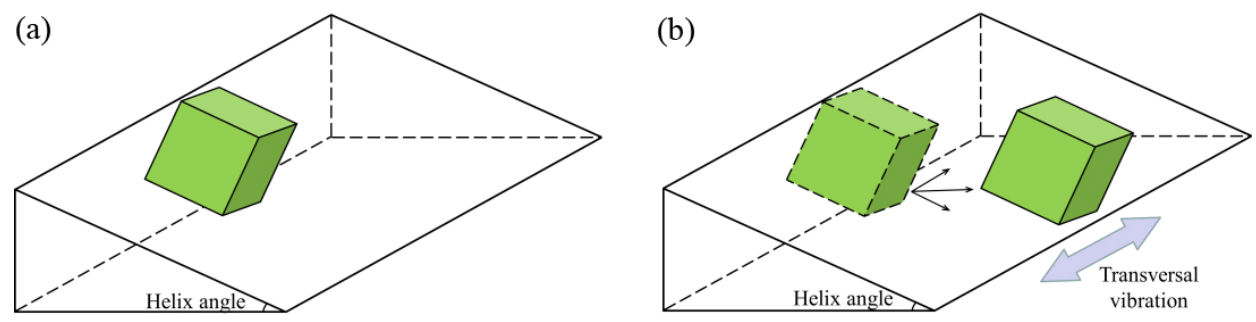

Fig. 6 Block on an incline analogy to a threaded fastener: (a) in the absence of any external vibration loading; (b) under a transverse vibration loading.

equation of critical slippage was derived. In 1982, Tanaka et al. [49] discussed the relationship between the axial tension and external loading by applying a numerical method to calculate the stress distribution on a threaded surface. In 1984, Yamamoto and Kasei [50] explained the mechanism of rotational loosening caused by a transverse vibration loading in terms of accumulation and release of potential energy owing to the torsional bolt deformation. During one half-cycle of vibration, the bolt threads first slid on the nut threads, producing an elastic torsional deflection. Then, the bearing surface was forced to slide on the moving plate, by which the torsional deflection was released and rotational loosening was produced. In 1988, Kasei et al. [51] proposed a novel mechanism of rotational loosening using a theoretical consideration. It was considered that rotational loosening on the thread surface could occur even when a macroscopic slide was absent on the bearing surface. This opinion was actually the beginning of the development of local slippage theory; however, subsequently, further attention was not paid to the same.

In 1989, Vinogradov and Huang [52] were the first to develop a dynamic model of a bolted joint to study rotational loosening. They performed numerical simulations to investigate the effect of the frequency of dynamic excitation on rotational loosening. It was found that rotational loosening was triggered by a non-uniform distribution of the preload along the threaded surface. In 1997, Zadoks et al. [53] presented an extensive study on the mechanism of rotational loosening by employing the theory of Hertz contact stress and a two-degree-of-freedom dynamic model. The main cause of rotational loosening was that the impact between the clamped mass and clamping bolt. In addition, the process of rotational loosening was also predicted based on the theoretical model. From the complete slippage theory, it was regarded that rotational loosening did not occur unless the pitch torque (denoted by $T_{\mathrm{p}}$ ) was larger than the sum of the friction torques of the bearing and threaded surfaces ( $T_{\mathrm{b}}$ and $T_{\mathrm{t}}$, respectively). Nassar et al. proposed linear [54] and nonlinear mathematical models [55] to calculate the above torques and obtained the change in the preload with increasing number of vibration cycles.

\subsubsection{Local slippage accumulation theory}

In 2002, Pai and Hess [56, 57] challenged the classical complete slippage theory. They observed the contact state of thread and bearing surfaces by FEA, and the hysteresis cycle experimentally. In the FEA, a bolted joint with a lead angle was established and the bottom plate was ignored for improving the calculation efficiency. It was found that complete slippage was not a necessary condition for rotational loosening. 
It was demonstrated that rotational loosening could still occur even when there were only partial slippage areas on the contact surfaces. The phenomenon, in which only partial areas on the contact surface slip, is referred to as the local slippage. They proposed that local slippage could gradually accumulate with an increase in the number of vibration cycles, as shown in Fig. 7(a), which was also able to cause rotational loosening and a large preload decrease, as shown in Fig. 7(b).

Local slippage accumulation theory has fundamentally changed the original understanding of the mechanism of rotational loosening and attracted the attention of numerous researchers. Subsequently, many scholars applied FEA method and theoretical analysis method to further research local slippage accumulation. In the FEA, two types of FE models were used. The former is the simplified FE model of a bolted joint without the bottom plate while the latter is the complete FE model made up of a bolt, nut, upper and bottom plates. In 2005, Izumi et al. [58] established a simplified FE model and found that local slippage accumulation could result in rotational loosening and inferred that rotational loosening was initiated when

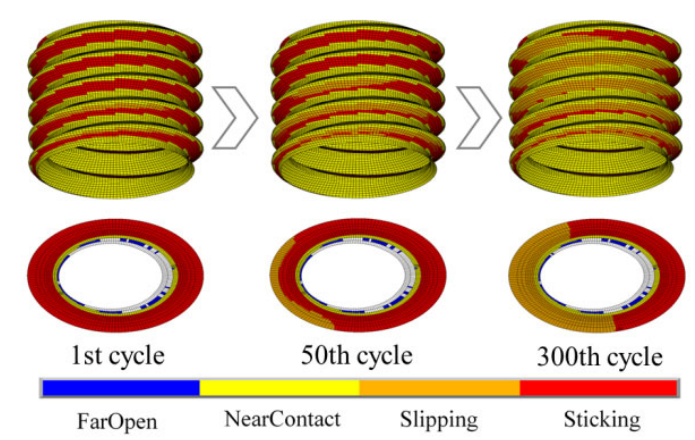

(a) Variation of contact states with increase in the number of vibration cycles

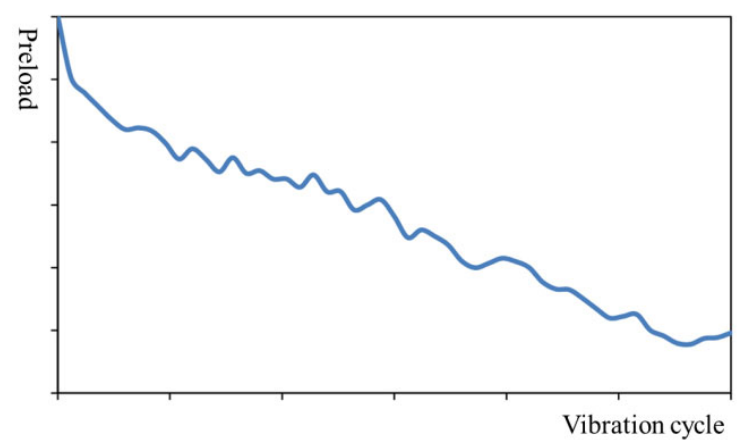

(b) Variation of preload with increase in the number of vibration cycles

Fig. 7 Schematic of local slippage accumulation and preload decrease under a transverse vibration. the thread surface reached a complete slip state, regardless of the slip state at the bearing surface. In another work, Izumi et al. [59] introduced the concept of micro-slip, which involves a no-constant-sticking region over a vibration cycle. They built a complete FE model and found that rotational loosening could proceed when either a micro-slip or a complete slip occurred. In 2007, Kasei [60] employed a theoretical analysis to study the rotational loosening caused by micro-slippage accumulation on a bearing surface. A theoretical explanation was presented on how rotational loosening occurred and grew larger. Zhang et al. [61] built a complete three-dimensional FE model of a bolted joint, simulated cyclic transverse vibration, and found that both the micro-slippage on the thread surface and cyclic change of the pressure on the thread surface initiated rotational loosening. In 2010, Yokoyama et al. [62] theoretically formulated an analytical model for describing the mechanical behaviour of a bolted joint subjected to a transverse loading. Based on the model, it was found that the inclination of the bolt affected the reaction moment during the local slippage on the thread surface, and finally caused rotational loosening. In 2011, Dinger and Friedrich [63] introduced a parameter, namely the ratio of the slip to the total contact area, to quantify the rotational loosening in their FEA (complete FE model) for analysing the local slippage and rotational loosening. In 2016, Dinger [64] employed complete FE model and an experimental method to study the local slippage of a bolted joint subjected to both torsional and transverse vibration loadings and obtained the critical condition for the rotational loosening caused by local slippage accumulation. In 2017, Chen et al. [65] conducted a complete three-dimensional elastic FEA to describe the slip states in greater detail, aiming to explore the mechanism of rotational loosening. The results revealed that the phenomenon of creep slip existed at the contact surface, which caused the loosening to occur even when some contact facets were stuck.

Recently, the authors proposed a modified Iwan model (2020) [66] to represent nonlinear local slippage behaviour. The acting forces on the internal thread were decomposed into three component forces along different directions. $F_{\mathrm{P}}, F_{\mathrm{S}}$, and $F_{\mathrm{R}}$ denote the three components along the $x-, y$-, and $z$-axes, respectively. 
The effect of each component on the local slippage accumulation was analysed theoretically based on the modified Iwan model. It was found that the cyclic component force along the radial direction dominated the local slippage accumulation of the thread surface, and the other two cyclic component forces had no effect on the local slippage accumulation. Then, the local slippage accumulation on the bearing surface was also analysed. Finally, a thorough understanding of the rotational loosening mechanism was developed.

\subsection{Torsional vibration loading}

Torsional vibration refers to the cyclic torque loading parallel to a nut or bolt axis. Clark and Cook [67] were, probably, the first to experimentally investigate the effect of fluctuating torque on rotational loosening. They studied the effect by conducting a series of tests on a bolt tightened into a tapped hole in a bar. A cyclic angular displacement could then be applied to the bar. A strain gauge was used to measure the bolt preload, while the test was being conducted. The results showed that rotational loosening was a function of both the oscillatory torque amplitude and bolt initial shank stress; accidental overloads contributed to more rotational loosening than did the repetitive oscillatory torques with small amplitude. Later, Sakai [68] further studied the mechanism of rotational loosening caused by torsional vibration loading through an experiment, and found that rotational loosening occurred only when loosening, tightening, and bearing torques satisfied a certain condition. This conclusion was validated recently by Yokoyama et al. [69] using an FEA. In addition, some researchers [70] also employed FEA to study the rotational loosening of a bolted joint subjected to translational and rotational vibration loadings. These studies indicated that the relationship between the radius of the pitch circle and that of the screw threads determines the magnitude of rotational loosening.

\subsection{Bending vibration loading}

Bending vibration refers to the cyclic torque loading perpendicular to a nut or bolt axis. The earliest research on the effect of bending vibration loading on rotational loosening was conducted by Haviland [71, 72] from Loctite Corporation. In this experiment, a simple composite cantilever beam comprising two steel blades bolted together was used to apply the bending loading. Side-sliding was proposed to explain the rotational loosening caused by bending loading, and it was found that the net effect, each time the nut was cycled sideways, was a ratcheting rotational loosening. The above experimental setting was also applied by other researchers to investigate the rotational loosening resulting from bending vibration loading. For example, Dong and Hess [73] studied the effect of thread dimensional conformance on loosening under bending vibration loading. The test apparatus used in these tests consisted of a compound beam mounted on a test fixture. The compound beam consisted of two pieces of 316L stainless steel, a test bolt and a test nut; two spacers were attached to the compound beam through a hole. The results showed that unqualified engaging threads would aggravate the rotational loosening. In another example using the same apparatus, Pai and Hess [74] studied the influence of fastener placement on bending-vibration-induced loosening and found that a fastener placed in certain regions of the assemblies was subjected to a higher shear force. Therefore, by avoiding fastener placement in such regions, the likelihood of fastener loosening was reduced. Du et al. [75] exploited an eccentric loading method to apply a bending vibration loading to a bolted joint. Their results indicated that plastic deformation and fretting wear primarily caused a preload loss; however no evident rotational loosening occurred. Moreover, Ishimura et al. [76] also conducted research on the loosening behaviour of a bolted flange structure subjected to cyclic bending vibration, and illuminated the loosening mechanism. The mechanism reported that external bending loading triggered slippage on the bearing surface of the flange structure and repeated slippage caused rotational loosening.

\subsection{Impact loading}

Impact represents the load acting on threaded fasteners at very high speeds within a very short period of time. The earliest reports documenting the research on rotational loosening of a bolted joint subjected to impact loading were the experiments conducted by Baubles et al. [77] and Faroni [78] from Elastic Stop Nut Corporation of the United States. The test apparatus 
consisted of spool-like arbours reciprocating within a slotted fixture. The arbours were held together by test nuts and bolts. The slotted fixture was vibrated at $30 \mathrm{~Hz}$ with a modified Sonntag universal fatigue testing machine, and at $60 \mathrm{~Hz}$ with an electromagnetic shaker. The results indicated that the number and magnitude of impact were the main factors that induced loosening failure; the frequency and direction (i.e., perpendicular or parallel to the bolt axis) of impact had no significant effect on the loosening. A theory on impact-induced loosening proposed that the impact acting on a bolted joint would cause the components to resonate and hence, loosening would occur. Subsequently, Koga [79] experimentally studied the loosening of threaded fasteners subjected to repeated impact loadings. In the experiment, a ball thrust bearing was inserted between the nut and a compression cylinder to eliminate the effect of friction on the nut base. The threads were lubricated with machine oil for all the tests. Four sash cords were used to lift and drop the bolt assembly along a guide cylinder, and an impact piece of the assembly struck a fixed stopper. The results indicated that the stress waves could change into tensile waves and decrease the shearing stress at the surface of the thread. The decrease in the shearing stress resulted in the slippage of the surface of the thread, and eventually, rotational loosening occurred. In another study, Koga [80] built a three-dimensional analytical geometry to quantitatively demonstrate the effect of thread angle on the loosening caused by impact. It was found that a comparatively strong loosening action was obtained when the thread angle was $60^{\circ}$ or less. Kasei and Matsuoka [81] further researched the mechanism of rotational loosening caused by impact loading. It was proposed that the elastic torsion of the bolt rod owing to a slippage between the internal and external threads was the main cause of rotational loosening. Dong and Hess [82] also conducted a significant experiment to analyse shock-induced rotational loosening of dimensionally non-conforming threaded fasteners.

In addition, some researchers employed a theoretical model or FEA to reveal the rotational loosening process caused by impact loading. For example, Daabin and Chow [83] developed a dynamic model to study impact-induced rotational loosening and investigate the influence of different parameters. It was concluded that the duration of the applied loading, leading angle, and surface friction played an important role in the loosening process. Shoji and Sawa [84] established a three-dimensional finite element model and simulated a bolted joint subjected to impact loading. The analytical results showed that the effect of impact on rotational loosening was evidently not different from that of vibration loading.

\section{Loosening curve under transverse vibration}

In the Sections 2 and 3, we have summarised different causes and mechanisms of the non-rotational and rotational loosening, respectively. Their comprehensive effects on loosening can be represented by loosening curve. The loosening curve denotes the relationship between the preload in a bolted joint and the service time. Most of the loosening curves are depicted under transverse vibrations; thus, the service time is represented by the number of vibration cycles. It is challenging to distinguish different causes and mechanisms in the loosening curve. This is also one purpose of investigating loosening curve. In addition, the loosening curve can be also employed to evaluate the fatigue life of threaded fasteners as well as compare the anti-loosening abilities of different threaded structures. Therefore, the research on the loosening curve is significant and has attracted much attention in the published literature.

\subsection{Loosening curve and cause analysis}

Early research on loosening curves was conducted by Jiang et al. [85]. In their experiment, it was observed that loosening started with a gradual relaxation of the initial preload without a reverse rotation between the internal and external threads. When the preload was reduced to below a certain critical value, the nut actually started to back off. Based on the observation, a typical sequence curve for preload decrease, including two distinct stages, was described as shown in Fig. 8(a). In the first stage [20], there was no relative rotation between the nut and bolt. This preload loss resulted from the local cyclic plasticity deformation occurring near the roots of the engaged threads. In the second stage [61], the local cyclic plasticity deformation will 


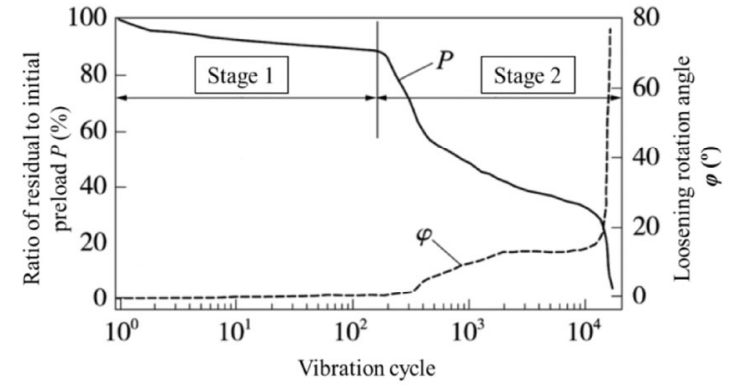

(a) Early loosening curve with two stages

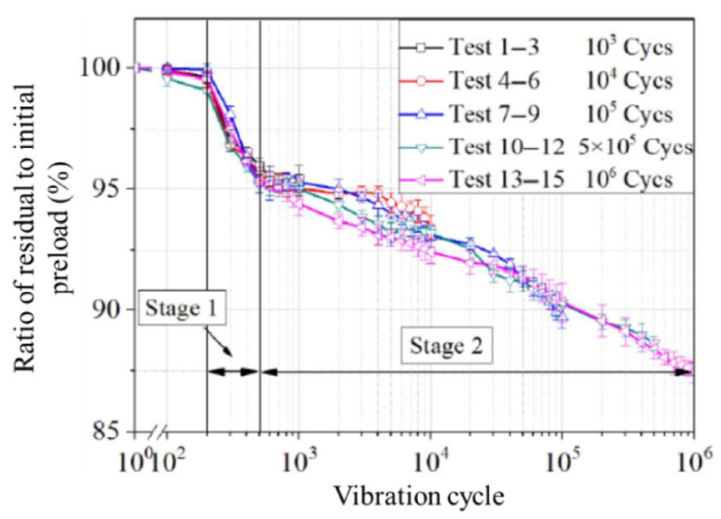

(b) Non-rotation loosening curve with two stages

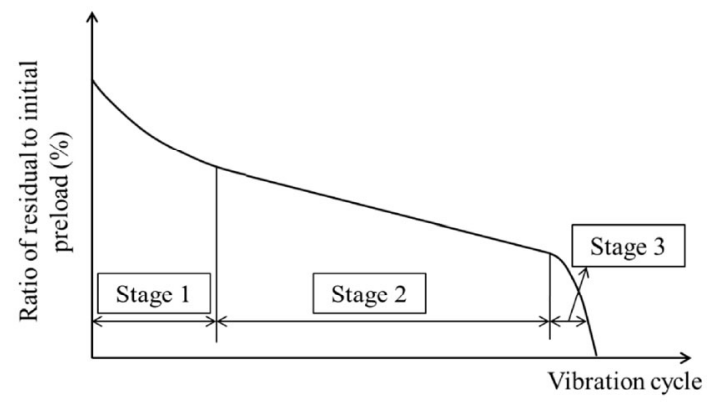

(c) New loosening curve with three stages

Fig. 8 Three loosening curves obtained from different sources in the literature.

no longer cause preload loss. The preload decreased rapidly, attributed to a significant rotation between the bolt and nut; there was a possible transition between the two stages.

The research of Jiang et al. only considered the non-rotational loosening caused by the change of material properties at the Stage 1. The explanation of the causes for the first loosening stage may not be sufficient. Zhang et al. [86] experimentally found that when the transversal displacement was smaller than $0.5 \mathrm{~mm}$, the rotational loosening would not occur. Therefore, the cyclic transversal displacement was set to be $0.25 \mathrm{~mm}$ in the vibration experiment and the curve of the non-rotational loosening was acquired as shown in Fig. 8(b). They further analyzed this curve and the corresponding causes. It can be seen clearly that the curve contains two different stages. Via SEM analysis, it was found that the preload loss at the first stage was caused by plasticity deformation, while that at the second stage resulted from a fretting wear on the thread surface. We guess that the preload will keep unchanged after enough vibration cycles.

Recently, Gong et al. [22, 23] established FE models of bolted joints with and without the helix angle. By comparison, they found a new important factor causing preload decrease at the stage of the non-rotational loosening and named it stress redistribution. Finally, a complete loosening curve comprising three different stages was depicted, as shown in Fig. 8(c). In Fig. 8(c), the influencing factors resulting in loosening at each stage were also analysed systematically. The complete loosening curve is made up of three stages. In Stage 1, the preload decreased nonlinearly owing to plastic deformation, stress redistribution, and rotational loosening. In Stage 2, the effects of plastic deformation and stress redistribution on the loosening were absent and the preload decreased linearly with rotational loosening. In Stage 3, the preload was decreased sharply owing to a fatigue fracture.

In Ref. [57], four different loosening processes have been proposed that are characterized by either complete or localized slip at the head and thread contacts. Therefore, different contact states will lead to different loosening processes and change the loosening curve. However, the previous research has not investigated this issue systematically. In the future, the nonlinear curve of the rotational loosening in Stage 2 due to the complete or localized slip at the head and thread contacts should be researched further.

\subsection{Numerical fitting of loosening curve}

One function of the loosening curve is to predict the fatigue life of threaded fasteners. Therefore, it is significant to quantify the loosening curve, especially the nonlinear stage of the non-rotational loosening. For this purpose, a numerical fitting of the loosening curve was conducted by researchers. Li et al. [87] found that the relationship between the preload and the vibration cycle at the initial stage conformed to a double-exponential equation: 


$$
F=A \cdot \mathrm{e}^{-\tau_{1} / N}+B \cdot \mathrm{e}^{-\tau_{2} / N}+C \cdot N+D
$$

where $F$ is the preload; $N$ is the vibration cycle; and $A, B, C, D, \tau_{1}$, and $\tau_{2}$ are the practical parameters of threaded fasteners. However, the above parameters had no clear meanings and are difficult to apply directly to engineering applications. Subsequently, $\mathrm{Wu}$ et al. [88] adopted the FE model to investigate the loosening behaviour of threaded fasteners. They proposed a novel prediction scheme based on the rotational loosening stiffness, comprehensively considering the influence of the preload, lateral force, and friction coefficient, as given in Eq. (2):

$$
k= \begin{cases}h\left[\left(c \mathrm{e}^{d \mu}+g\right)(a f+b)\right], & f \geq f_{0} \\ 0, & f \leq f_{0}\end{cases}
$$

where $k$ is the stiffness of rotational loosening; $\mu$ is the friction coefficient of the threaded surface; $f$ is the transversal force; $f_{0}$ is the critical transverse force; $h$ is the influence coefficient of preload; $a$ and $b$ are the influence coefficients of transversal force; and $c, d$, and $g$ are the influence coefficients of the friction coefficient.

Currently, only the loosening curve at the nonlinear stage has been fitted numerically; the universality of the fitted equation requires to be validated further. In addition, the numerical fitting of the complete loosening curve is also an unsolved issue due to containing abundant unknown parameters.

\section{Critical condition of loosening}

The seriousness of the damage caused by loosening is self-evident. To avoid loosening in practical engineering applications and improve the reliability of products, research on the critical condition of loosening has attracted the attention of numerous researchers. It is widely recognized that transverse vibration is the main loading form that results in loosening. Therefore, existing studies on the critical condition of loosening have been mainly based on transverse vibration loading. The stage of non-rotational loosening is usually temporary and will disappear after a certain vibration cycles. Therefore, the critical condition of loosening refers to the critical condition where the stage of rotational loosening will not appear.
According to two different theories (i.e., complete slippage and local slippage accumulation theories), we have divided these studies into two categories, which are summarised in Table 4.

\subsection{Based on complete slippage theory}

Back in 1969, Junker [36], who was a pioneer in this area, proposed that loosening originated from a complete slippage on the bearing and thread surfaces (i.e., complete bearing and thread slippages) and the complete bearing slippage was the critical condition for loosening because it followed the complete thread slippage. The German national standard VDI 2230 [11] adopted this view and suggested that the working loading should not cause the bearing surface to completely slip when designing bolted joints. In addition, the critical transversal displacement (i.e., the vibration amplitude) corresponding to the complete bearing slippage was used as a criterion indicating the occurrence of loosening. Nishimura et al. [89, 90] proposed the critical relative slippage (Scr), below which threaded fasteners would remain fastened. This Scr was estimated according to a theoretical equation, considering the bolt bending and the geometrical constraint condition. In other studies, the nonlinearity of inclination compliance $(\mathrm{kw})$ with respect to the bolt axial tension was also considered [90, 91]. Additionally, Hattori et al. [92] developed a more accurate equation for calculating Scr by presenting a new prediction equation for the reaction moment $\mathrm{Mn}$.

Nassar's group investigated the critical condition of loosening theoretically when the frictional forces on the bearing and thread surfaces were overcome simultaneously. Nassar and Housari [54] assumed the threaded fastener to be a free body and established linear and angular equations of motion for a mathematical model for threaded fasteners. It was found that a threshold level of preload under a known excitation amplitude existed, below which loosening would begin. The critical preload value was higher for a fine thread than for a coarse thread. In another paper, they [93] demonstrated that a combination of thresholds of thread and bearing friction coefficients existed, below which loosening started. Nassar and Yang [55] established more effective mathematical models for describing the bearing and thread torques 
Table 4 Summary of research work on critical condition of loosening.

\begin{tabular}{|c|c|c|c|}
\hline Theoretical basis & Scholars and Ref. & Method & Progress \\
\hline \multirow{4}{*}{$\begin{array}{l}\text { Complete } \\
\text { slippage theory }\end{array}$} & Junker [36] & Experiment & Loosening originates from a complete bearing slippage. \\
\hline & $\begin{array}{l}\text { Nishimura et al. } \\
{[89,90]}\end{array}$ & Theoretical model & Proposed the theoretical equation of critical relative slippage. \\
\hline & $\begin{array}{l}\text { Nassar's group } \\
{[54,55,93-98]}\end{array}$ & Theoretical model & $\begin{array}{l}\text { Proposed the criterion for preventing loosening and evaluated the } \\
\text { criterion of loosening under different factors. }\end{array}$ \\
\hline & Sun et al. [99] & Theoretical model & $\begin{array}{l}\text { Proposed an analytical method for calculating the critical transverse } \\
\text { loading. }\end{array}$ \\
\hline \multirow{7}{*}{$\begin{array}{l}\text { Local slippage } \\
\text { accumulation } \\
\text { theory }\end{array}$} & Pai and Hess $[56,57]$ & FEA & $\begin{array}{l}\text { Loosening was initiated when the transversal displacement reached } \\
\text { approximately } 46 \%-66 \% \text { of Scr. }\end{array}$ \\
\hline & Izumi et al. [58] & FEA & $\begin{array}{l}\text { Loosening was initiated when the thread surface reached a complete } \\
\text { slip state regardless of the slip state at the bearing surface. }\end{array}$ \\
\hline & Izumi et al. [59] & FEA & $\begin{array}{l}\text { Loosening rotation can proceed when either a micro-slip or complete } \\
\text { slip occurred. }\end{array}$ \\
\hline & Dinger et al. [63] & FEA & $\begin{array}{l}\text { The transverse displacement causing loosening could be as low as } \\
0.55 \mathrm{~mm} \text {, whereas the value of Scr corresponding to complete bearing } \\
\text { slip was } 0.86 \mathrm{~mm} \text {. }\end{array}$ \\
\hline & Dinger [64] & FEA and experiment & $\begin{array}{l}\text { Used the critical loosening gradient of a screw head, i.e., } 0.01 \% \text { cycle, } \\
\text { to evaluate whether a bolted joint was loosening. }\end{array}$ \\
\hline & Zhang et al. [100] & Theoretical model & Obtained a numerical formula for critical loading for bolt loosening. \\
\hline & Gong et al. [101] & FEA & $\begin{array}{l}\text { Developed a novel simulation method, including two stages to clearly } \\
\text { monitor the real rotation-induced loosening. }\end{array}$ \\
\hline
\end{tabular}

and obtained more accurate analytical results. This indicated that both the bearing and thread torques were able to reach zero, when the transversal amplitudes were sufficiently large, which laid the foundation for the critical condition of loosening. Based on the above mathematical models, Yang and Nassar [94] obtained a theoretical equation of preload change per cycle under transverse vibration. The loosening curves were depicted and they showed that for a certain vibration amplitude, the preload could remain unchanged when the preload was large, while it decreased sharply when the preload was small. Subsequently, Yang et al. [95] proposed a criterion for preventing loosening. In addition, Zaki et al. [96-98] also established a mathematical model of preloaded countersunk head bolts under a periodic transverse excitation and investigated the critical condition for loosening under different parameters. Based on the mathematical models proposed by Nassar et al., Sun et al. [99] established an improved mathematical model representing the mechanical behaviour of a bolted joint. An analytical method for calculating the critical transverse load was proposed, which improved the calculation efficiency and precision.

\subsection{Based on local slippage accumulation theory}

In the early $21^{\text {st }}$ century, Pai and Hess $[56,57]$ found that loosening could occur prior to a complete bearing slip (i.e., there are only some local slip areas on the bearing and thread surfaces) and proposed the local slippage accumulation theory. This means that loosening can still occur when the transverse displacement is less than Scr. It was observed experimentally that loosening was initiated when the transverse displacement reached approximately $46 \%-66 \%$ of Scr. Izumi et al. [58] found that loosening was initiated when the thread surface reached a complete slip state regardless of the slip state at the bearing surface. In another study, Izumi et al. [59] introduced the concept of micro-slip, which involves no constant-sticking region over a vibration cycle. They found that loosening rotation could proceed when either a micro-slip or complete slip occurred. In addition, it was calculated by FEA that a small degree of loosening was initiated when the vibration force reached approximately $50 \%-60 \%$ of the critical loading necessary for complete bearing slippage. Dinger et al. [63] found that for a specific threaded fastener, the 
transverse displacement causing loosening could be as low as $0.55 \mathrm{~mm}$, whereas the value of Scr corresponding to a complete bearing slip was $0.86 \mathrm{~mm}$. Dinger [64] used the critical loosening gradient of a screw head, i.e., $0.01 \%$ cycle, to evaluate whether a bolted joint was loosening.

Recently, Zhang et al. [100] regarded inhibiting the localised thread slip as the condition for avoiding loosening and obtained a numerical formula for critical loading for loosening through a force analysis in different circumferential positions of the thread. The theoretical results were proved by experiments. Gong et al. [22, 23] found that it was difficult to identify the critical transverse force for initiating loosening using a traditional finite element simulation owing to stress redistribution. Therefore, they developed a novel simulation method that included two stages to clearly monitor the real rotation-induced loosening [101]. In the first stage, a large transverse force was initially applied to accelerate the stress release/redistribution.
In the second stage, a small force was used to identify the critical features of loosening. A new loosening criterion was also proposed.

In summary, rotational loosening was initially regarded as originating from both a complete slippage on both the bearing and thread surfaces. Accordingly, a complete bearing slippage was the critical condition for loosening because it generally followed the complete thread slippage. Therefore, the preload should be large enough to avoid a complete slippage of the bearing surface caused by external loadings during the design of a bolted joint as per the German standard VDI 2230. A theoretical equation for calculating the critical transversal displacement or force was developed based on the complete slippage theory. However, it was found that a small transversal displacement or force could also induce loosening owing to the local slippage accumulation of the bearing and threaded surfaces. Therefore, the critical transverse displacement or force based on the local

Table 5 Summary of research work on influencing factors of loosening.

\begin{tabular}{|c|c|c|}
\hline Method & Scholars and Ref. & Influencing factors \\
\hline \multirow{6}{*}{ Experiments } & Finkelston [105] & Amplitudes, thread pitches, initial preloads, and bearing surface conditions \\
\hline & Walker [106] & $\begin{array}{l}\text { Preload, prevailing torque, thread pitch, surface coating, thread pitch diameter } \\
\text { clearance, and their combinations }\end{array}$ \\
\hline & Sanclemente and Hess [107] & $\begin{array}{l}\text { Preload, elastic modulus, nominal diameter, thread pitch, hole fit, lubrication, and } \\
\text { their interactions }\end{array}$ \\
\hline & Zhang et al. [108] & Loading direction and clamped length \\
\hline & Marshall et al. [109] & Stress distribution \\
\hline & Noda et al. [110] & Fit clearance of thread \\
\hline \multirow{7}{*}{ FEA } & Zhu et al. [112] & Transverse frequency, amplitude, friction coefficient, and initial preload \\
\hline & Wang et al. $[113,114]$ & Pitch, hole clearance, vibration amplitude, initial preload, and friction coefficients \\
\hline & Hou and Liao [115] & $\begin{array}{l}\text { Increment step length, initial clamping force, amplitude of the shear load, thread } \\
\text { tolerance, and friction coefficients }\end{array}$ \\
\hline & Gong et al. [101] & $\begin{array}{l}\text { Initial preload, frictional coefficients at the thread and bearing surfaces, clamped } \\
\text { length, nominal diameter of the bolted joint, material type, and fit tolerance }\end{array}$ \\
\hline & Xu et al. [116] & Preload, vibration amplitude, and friction coefficient \\
\hline & Liu [117] & load amplitude, initial preload, and friction coefficient \\
\hline & Sawa and Ishimura [118] & Inclination angle of the bearing surface \\
\hline \multirow{4}{*}{$\begin{array}{l}\text { Theoretical } \\
\text { models }\end{array}$} & $\begin{array}{l}\text { Nassar et al. } \\
{[54,55,97,119-124]}\end{array}$ & $\begin{array}{l}\text { Thread pitch, initial preload, friction coefficients on the bearing and thread surfaces, } \\
\text { hole clearance, thread fitting clearance, non-parallel contact of the bearing surface, } \\
\text { and thread profile angle }\end{array}$ \\
\hline & Chen et al. [125] & Thread lead angle, initial preload, vibration frequency, and nature of material \\
\hline & Fernando [126] & Various thread parameters \\
\hline & Fort et al. [127] & Clamping length \\
\hline
\end{tabular}


slippage accumulation theory is more accurate. Vibration experiments and finite element simulations can be applied to accurately determine the same for a given bolted joint. However, an analytical solution for the same, based on local slippage accumulation could not be developed because it was difficult to quantify the local slippage accumulation.

\section{Influencing factors of loosening}

Numerous studies have been conducted to evaluate the effects of various factors on loosening under transverse vibrations to seek a good anti-loosening strategy. The loosening discussed in this section refers to the whole loosening behavior of a bolted joint (i.e., the whole preload decrease). Scholars did not analyze the effects of various factors on preload decrease for different stages. Common research methods include experiments, FEA, and theoretical modelling. The existing literature on the above methods is summarised in Table 5.

\subsection{Experimental work}

The Junker transversal vibration test is a standard experimental method to assess the loosening behaviour or the anti-loosening ability of a bolted joint, which is illustrated in detail in both national [102, 103] and international [104] standards. Some researchers applied the Junker machine to analyse the effects of various factors on loosening. Specifically, Finkelston [105] systematically assessed the abilities of different amplitudes, thread pitches, initial preloads, and bearing surface conditions with regard to resistance to loosening. It was found that reducing the amplitude and thread pitch, increasing the initial preload, and employing a hard material could decrease the loosening. Walker [106] used a fractional factorial experiment design to investigate the influence of several factors on vibration-induced loosening. The evaluated factors were preload, prevailing torque, thread pitch, surface coating, thread pitch diameter clearance, and their combinations. The results showed that thread pitch had the largest influence on loosening, followed by prevailing torque, interaction of thread pitch and prevailing torque, thread pitch diameter clearance, preload, and surface coating. Sanclemente and Hess [107] performed sixty-four tests as a part of a nested-factorial design and applied statistical analysis techniques to identify the influence level of preload, elastic modulus, nominal diameter, thread pitch, hole fit, lubrication, and their interactions. It was found that the optimum conditions to reduce loosening were a high preload, low elasticity modulus, large diameter, lubrication, tight fit, and fine threads. Zhang et al. [108] experimentally studied the effects of the loading direction and clamped length on loosening. Their results showed that increasing the clamped length and angle of the external load with the pure shearing direction could reduce loosening.

Additionally, some non-standard experimental methods were also employed to conduct a factorial analysis of loosening. For example, Marshall et al. [109] made use of an ultrasonic equipment to design a simple apparatus to investigate the loosening behaviour under different stress distributions. Noda et al. [110] also designed an experimental setting to investigate the effect of fit clearance of internal and external threads on loosening.

\subsection{FEA}

With the improvement of computing power, it is now possible to establish an accurate finite element model of threaded fasteners and simulate the cyclic transversal vibration, based on which some influencing factors can be analysed. Some researchers adopted Fukuoka and Nomura's method [111] to generate an orderly three-dimensional hexahedral mesh for bolted joints. Based on an accurate finite element model, Zhu et al. [112] discussed the influences of transverse frequency, amplitude, friction coefficient, and initial preload on the residual preload within a specific amount of time. Wang et al. [113, 114] considered five influencing factors, namely, pitch, hole clearance, vibration amplitude, initial preload, and friction coefficients. It was found that loosening was more difficult to occur under a fine thread, small excitation amplitude and initial preload, and large thread and bearing friction coefficients. Hou and Liao [115] investigated the effect of increment step size, initial clamping force, amplitude of the shear load, thread tolerance, and friction coefficients on the loosening process. An important finding was related to the friction coefficients, which indicated that the bolted joint would not loosen when the two coefficients 
were significantly different from each other. In addition, Gong et al. [101] evaluated various influencing factors, such as initial preload, frictional coefficients at the thread and bearing surfaces, clamped length, nominal diameter of the bolted joint, material type, and fit tolerance from the perspective of critical transverse force. The results indicated that the preload, frictional coefficients at the thread and bearing surfaces, clamped length, and fit tolerance were the prominent factors that affected loosening. When the preload and friction coefficients were increased, and the clamped length and fit tolerance were reduced, loosening was inhibited.

Accurate hexahedral meshes for thread structures generally entail a large computing cost. Therefore, some researchers have employed free meshes to divide the thread structures with high efficiency. Xu et al. [116] analysed the effects of preload, vibration amplitude, and friction coefficient on loosening. Liu [117] established an FE model of the threaded fasteners of a $12 \mathrm{kV}$ vacuum circuit breaker, used in power systems. The relationship between the loosening and load amplitude, the initial preload, and the friction coefficient was discussed. In addition, Sawa and Ishimura [118] studied the effects of the inclination angle of the bearing surface on loosening.

\subsection{Theoretical model}

As stated in Section 5.1, Nassar's group established both linear and nonlinear mathematical models to describe the relationship between the tightening force and torques applied to a bolted joint. Using their models, they systematically investigated the effects of thread pitch [54], initial preload [54], friction coefficients on the bearing and thread surfaces [97], hole clearance [119], thread fitting clearance [119], non-parallel contact of bearing surface [120], and thread profile angle [121] on loosening. It was found that under a known excitation amplitude, the bolted joint with the coarse thread, small preload and friction coefficients, large hole clearance, and loose thread fitting clearance would loosen at a higher rate. The analytical results also demonstrated that increasing the contact wedge angle and thread profile would improve the loosening resistance. Additionally, they built a mathematical model [98] to describe the mechanical behaviour of countersunk head screws and investigated the influence of cone angle [96], pitch [96], and friction coefficients of bearing and thread surfaces [97] on loosening.

For example, Chen et al. [122] derived static and dynamic models for threaded fasteners to find the static and dynamic interior forces, respectively. The threaded fastener looseness model was constructed by combining the above models with a Karnopp frictional model to study the effects of thread lead angle, initial preload, vibration frequency, and the nature of the material on the bolt looseness. Fernando [123] established a mathematical model to reveal the influence of various thread parameters on loosening and connection integrity. Recently, Fort et al. [124] improved the theoretical models proposed by Nassar et al. [55] and studied the influence of clamping length on the loosening of threaded fasteners.

In summary, it can be concluded from above research work that an increase in the preload, friction coefficients of the bearing and thread surfaces [125], or clamped length; and a decrease in the hole clearance, thread fitting clearance, thread pitch, or elastic modulus contribute to an improved resistance to loosening. In addition, for a known external vibration load, the axial direction of the threaded fasteners should be designed to be parallel to the vibration direction to the extent possible to enhance the anti-loosening performance. However, the previous research mainly focused on the effects of various factors on the whole preload decrease. The influencing factors for different loosening stages or loosening mechanisms have not been analyzed systematically, which deserves to be researched further in the future.

\section{Conclusions and prospects}

In this review, we have systematically summarised the research status on the loosening of threaded fasteners. From the existing literature, we can conclude that loosening is attributed to the change of material properties and the effect of external vibration loading. The loosening mechanism has been clarified qualitatively. Briefly, when threaded fasteners are in a static state, embedding loss, creep, and stress relaxation contribute to non-rotational loosening. When threaded fasteners are subjected to cyclic dynamic loadings, both nonrotational and rotational loosening could occur at the 
same time. Specifically, plastic deformation, fretting wear, and stress redistribution dominate the nonrotational loosening, while periodic transverse vibration mainly results in large-scale rotational loosening. With regard to rotational loosening under a transverse vibration, the existing research has shown that local slippage accumulation is the primary mode to generate this type of loosening. In addition, a complete loosening process under transverse vibration, comprising three different stages has also been revealed.

In the future, more quantitative research work should be conducted. For example, the question of how we can mathematically describe and represent the accumulation and evolution of the local slippage on a threaded surface should be answered. Efforts should be expended to build a model that quantitatively depicts the relationship between the local slippage accumulation and preload loss to report the loosening mechanism absolutely. These studies will provide a quantitative foundation for the anti-loosening design of threaded fasteners.

Furthermore, measuring, analysing, and predicting the loosening behaviour of threaded fasteners in an actual service environment is another research direction, to which more attention should be paid in the future. On the one hand, the actual service environment is complicated, containing various coupled and nonlinear loadings, and not a pure or sinusoidal transverse vibration loading. On the other hand, more accurate and quantitative results reflecting the actual loosening process are lacking. Therefore, the key issue to be addressed is to mimic various coupled and nonlinear loadings, based on which, quantitative research on loosening using experiments and FEA can be conducted. It is believed that quantitative measurements and predictions of loosening in an actual service environment will be crucial for improving the service reliability of threaded fasteners.

Finally, the critical condition for loosening has been assessed qualitatively and some factors influencing the same have been investigated. In general, the ratio of the critical transverse force causing a loosening to the transverse force causing a complete bearing slippage is a quantitative index for the critical condition for loosening. The larger the index, the better the anti-loosening performance. Existing research has found that the index will be reduced when the friction coefficients on the thread and bearing surfaces decrease significantly. When the fit tolerance between the internal and external threads becomes small, especially the interference fit, the index may apparently increase. However, accurate critical conditions still require to be determined because research on the effects of coupled factors on loosening is still lacking. Currently, it is a big challenge to establish a theoretical model to accurately and quantitatively represent the preload decrease or rotation angle caused by local slippage accumulation. A large number of experiments and simulations, considering various parameters and their interactions may provide a solution. In this way, the actual design and assembly of threaded fasteners can be properly guided for a strong anti-loosening performance.

\section{Acknowledgements}

The authors are grateful for support by the National Natural Science Foundation of China (Nos. 51935003 and 51675050), and the National Defense Fundamental Research Foundation of China (No. JCKY2016204B201).

Open Access This article is licensed under a Creative Commons Attribution 4.0 International License, which permits use, sharing, adaptation, distribution and reproduction in any medium or format, as long as you give appropriate credit to the original author(s) and the source, provide a link to the Creative Commons licence, and indicate if changes were made.

The images or other third party material in this article are included in the article's Creative Commons licence, unless indicated otherwise in a credit line to the material. If material is not included in the article's Creative Commons licence and your intended use is not permitted by statutory regulation or exceeds the permitted use, you will need to obtain permission directly from the copyright holder.

To view a copy of this licence, visit http://creativecommons.org/licenses/by/4.0/.

\section{Reference}

[1] Bickford J H. An Introduction to the Design and Behavior of Bolted Joints. 3rd ed. New York (USA): Marcel Dekker Inc., 1995. 
[2] Towsyfyan H, Gu F S, Ball A D, Liang B. Tribological behaviour diagnostic and fault detection of mechanical seals based on acoustic emission measurements. Friction 7(6): 572-586 (2019)

[3] Holmes H. Seeking the perfect locking method for threaded fasteners. Automat 35(3): 28-30, 32 (1988)

[4] Department for Transport UK. Rail accident investigation branch reports. https://www.gov.uk/raib-reports, 2020.

[5] Tencent news. Safety accident of space trek amusement project in OCT East of Shenzhen. https://news.qq.com/ a/20100630/000020.htm, 2020.

[6] Pai N G. Vibration induced loosening of threaded fasteners: mechanisms, modeling and design guidelines. Ph.D. Thesis. Florida (USA): University of South Florida, 2002.

[7] Eccles M. Tribological aspects of the self-loosening of threaded fasteners. Ph.D. Thesis. Lancashire (England): University of Central Lancashire, 2010.

[8] Kakirde A, Dravid S. Study of vibration loosening of bolted joints-A review. J Xidian Univ 13(1): 11-20 (2019)

[9] Kakirde A, Dravid S. A review on loosening of bolted joints. Int J Adv Res Sci Eng 6(1): 988-997 (2017)

[10] Meyer G, Strelow D. How to calculate preload loss due to permanent set in bolted joints. Assembly Eng (1972)

[11] Norm of the Association of German Engineers (VDI) 2230-1: 2014, Systematic calculation of high duty bolted joints: Joints with one cylindrical bolt.

[12] Denkert C, Kalkowsky F, Flügge W. Experimental studies on the clamp length diameter ratio in highly stressed bolted joints. In $24^{\text {ème }}$ Congrès Français de Mécanique, Brest, 2019.

[13] Chung P P, Wang J, Durandet Y. Deposition processes and properties of coatings on steel fasteners-A review. Friction 7(5): 389-416 (2019)

[14] Fisher J W, Struik J H A. Guide to Design Criteria for Bolted and Riveted Joints. New York (USA): Wiley, 1974.

[15] Abboud A, Nassar S A. Viscoelastic strain hardening model for gasket creep relaxation. J Press Vess Technol 135: 031201 (2013)

[16] Yang J, DeWolf J T. Mathematical model for relaxation in high-strength bolted connections. J Struct Eng 125(8): 803-809 (1999)

[17] Tendo M, Yamada K, Shimura Y. Stress relaxation behavior at high-tension bolted connections of stainless-steel plates. J Eng Mater Technol 123(2): 198-202 (2001)

[18] Guo J Q, Zheng X T, Zhang Y, Shi H C, Meng W Z. A unified continuum damage mechanics model for predicting the stress relaxation behavior of high-temperature bolting. J Press Vess Technol 136: 011203 (2014)
[19] BS EN 10319-2:2006 Metallic materials. Tensile stress relaxation testing. Procedure for bolted joint models. British Standards, 2006.

[20] Jiang Y Y, Zhang M, Lee C H. A study of early stage self-loosening of bolted joints. J Mech Des 125(3): 518-526 (2003)

[21] Hou S Y, Liao R D. Influence of ratcheting on self-loosening of bolted joints. Trans Beijing Inst Technol 35(9): 924-930 (2015)

[22] Gong H, Liu J H, Ding X Y. Study on the mechanism of preload decrease of bolted joints subjected to transversal vibration loading. Proc Inst Mech Eng B-J Eng Manuf 233(12): 2320-2329 (2019)

[23] Gong H, Liu J H, Ding X Y. Study on the mechanism and influencing factors of preload decline for bolted joints under vibration. J Mech Eng 55(11): 138-148 (2019)

[24] Cai Z B, Chen Z Q, Sun Y, Jin J Y, Peng J F, Zhu M H. Development of a novel cycling impact-sliding wear rig to investigate the complex friction motion. Friction 7(1): 32-43 (2019)

[25] Liu J H, Ouyang H J, Peng J F, Zhang C Q, Zhou P Y, Ma L J, Zhu M H. Experimental and numerical studies of bolted joints subjected to axial excitation. Wear 346-347: 66-77 (2016)

[26] Liu J H, Ouyang H J, Feng Z Q, Cai Z B, Liu X T, Zhu M H. Study on self-loosening of bolted joints excited by dynamic axial load. Tribol Int 115(5): 432-451 (2017)

[27] Zhou J B, Liu J H, Ouyang H J, Cai Z B, Peng J F, Zhu M H. Anti-loosening performance of coatings on fasteners subjected to dynamic shear load. Friction 6(1): 32-46 (2018)

[28] Zhang M Y, Lu L T, Wang W J, Zeng D F. The roles of thread wear on self-loosening behavior of bolted joints under transverse cyclic loading. Wear 394-395: 30-39 (2018)

[29] Zhang M Y, Zeng D F, Lu L T, Zhang Y B, Wang J, Xu J M. Finite element modelling and experimental validation of bolt loosening due to thread wear under transverse cyclic loading. Eng Fail Anal 104(3): 341-353 (2019)

[30] Goodier J N, Sweeney R J. Loosening by vibration of threaded fastenings. Mech Eng 67: 798-802 (1945)

[31] Sauer J A, Lemmon D C, Lynn E K. Bolts: How to prevent their loosening. Mach Des 22: 133-139 (1950)

[32] Paland E G. Investigation of the locking features of dynamically loaded bolted connections. Ph.D. Thesis. Hannover (Germany): University of Hannover, 1966.

[33] Gambrell S C. Why bolts loosen. Mach Des 40: 163-167 (1968)

[34] Hongo K. Loosening of bolt and nut fastening. Trans Jpn Soc Mech Eng 30: 215 (1964) 
[35] Sakai T. Investigations of bolt loosening mechanisms: 3rd report, on the bolts tightened over their yield point. Bull JSME 22(165): 412-419 (1979)

[36] Junker G H. New criteria for self-loosening of fasteners under vibration. SAE Trans 78: 314-355 (1969)

[37] Hess D P. Threaded components under axial harmonic vibration, part 2: kinematic analysis. J Vib Acoust 118(3): 423-429 (1996)

[38] Hess D P, Davis K. Threaded components under axial harmonic vibration, part 1: experiments. J Vib Acoust 118(3): 417-422 (1996)

[39] Hess D P, Sudhirkashyap S V. Dynamic analysis of threaded fasteners subjected to axial vibration. $J$ Sound Vib 193(5): 1079-1090 (1996)

[40] Hess D P, Sudhirkashyap S V. Dynamic loosening and tightening of a single-bolt assembly. $J$ Vib Acoust 119(3): 311-316 (1997)

[41] Basava S, Hess D P. Bolted joint clamping force variation due to axial vibration. J Sound Vib 210(2): 255-265 (1998)

[42] Izumi S, Take T, Kimura M, Sakai S. Self-loosening analysis of bolt-nut tightening system subjected to axial loading by three-dimensional finite element method. Trans Jpn Soc Mech Eng Ser A 73(732): 869-876 (2007)

[43] Sakai T. Mechanism for a bolt and nut self loosening under repeated bolt axial tensile load. J Solid Mech Mater Eng 5(11): 627-639 (2011)

[44] Nassar S A, Yang X J, Gandham S V T, Wu Z J. Nonlinear deformation behavior of clamped bolted joints under a separating service load. J Press Vess Technol 133(2): 021001 (2011)

[45] Yang X J, Nassar S A, Wu Z J, Meng A D. Nonlinear behavior of preloaded bolted joints under a cyclic separating load. J Press Vess Technol 134(1): 011206 (2012)

[46] Meng Y G, Xu J, Jin Z M, Prakash B, Hu Y Z. A review of recent advances in tribology. Friction 8(2): 221-300 (2020)

[47] Yamamoto A, Kasei S. Investigations on the self-loosening of threaded fasteners under transverse vibration. J Jpn Soc Precis Eng 43(508): 470-475 (1977)

[48] Sakai T. Investigations of bolt loosening mechanisms: 1st report, on the bolts of transversely loaded joints. Bull JSME 21(159): 1385-1390 (1978)

[49] Tanaka M, Hongo K, Asaba E. Finite element analysis of the threaded connections subjected to external loads. Bull JSME 25(200): 291-298 (1982)

[50] Yamamoto A, Kasei S. A solution for self-loosening mechanism of threaded fasteners under transverse vibration. Bull Jpn Soc Precis Eng 18(3): 261-266 (1984)

[51] Kasei S, Ishimura M, Ohashi N. On self-loosening of threaded joints in the case of absence of macroscopic bearing-surface sliding. Loosening mechanism under transversely repeated force. J Jpn Soc Precis Eng 54(7): 1381-1386 (1988)

[52] Vinogradov O, Huang X. On a high frequency mechanism of self-loosening of fasteners. In Proceedings of 12th ASME Conference on Mechanical Vibration and Noise, Montreal, Quebec, 1989: 131-137.

[53] Zadoks R I, Yu X. An investigation of the self-loosening behavior of bolts under transverse vibration. J Sound Vib 208(2): 189-209 (1997)

[54] Nassar S A, Housari B A. Effect of thread pitch and initial tension on the self-loosening of threaded fasteners. J Press Vess Technol 128(4): 590-598 (2006)

[55] Nassar S A, Yang X J. A mathematical model for vibrationinduced loosening of preloaded threaded fasteners. $J$ Vib Acoust 131(2): 021009 (2009)

[56] Pai N G, Hess D P. Experimental study of loosening of threaded fasteners due to dynamic shear loads. J Sound Vib 253(3): 585-602 (2002)

[57] Pai N G, Hess D P. Three-dimensional finite element analysis of threaded fastener loosening due to dynamic shear load. Eng Fail Anal 9(4): 383-402 (2002)

[58] Izumi S, Yokoyama T, Iwasaki A, Sakai S. Three-dimensional finite element analysis of tightening and loosening mechanism of threaded fastener. Eng Fail Anal 12(4): 604-615 (2005)

[59] Izumi S, Kimura M, Sakai S. Small loosening of bolt-nut fastener due to micro bearing-surface slip: A finite element method study. J Solid Mech Mater Eng 1(11): 1374-1384 (2007)

[60] Kasei S. A study of self-loosening of bolted joints due to repetition of small amount of slippage at bearing surface. J Adv Mech Des, Syst, Manuf 1(3): 358-367 (2007)

[61] Zhang M, Jiang Y Y, Lee C H. Finite element modeling of self-loosening of bolted joints. J Mech Des 129(2): 218-226 (2007)

[62] Yokoyama T, Izumi S, Sakai S. Analytical modelling of the mechanical behavior of bolted joint subjected to transverse loading. J Solid Mech Mater Eng 4(9): 1427-1443 (2010)

[63] Dinger G, Friedrich C. Avoiding self-loosening failure of bolted joints with numerical assessment of local contact state. Eng Fail Anal 18(8): 2188-2200 (2011)

[64] Dinger G. Design of multi-bolted joints to prevent selfloosening failure. Proc Inst Mech Eng C: J Mech Eng Sci 230(15): 2564-2578 (2016)

[65] Chen Y, Gao Q, Guan Z Q. Self-loosening failure analysis of bolt joints under vibration considering the tightening process. Shock Vib 2017: 2038421 (2017)

[66] Gong H, Liu J H, Ding X Y. Thorough understanding on the mechanism of vibration-induced loosening of threaded fasteners based on modified Iwan model. J Sound Vib 
473(159): 115238 (2020)

[67] Clark S K, Cook J J. Vibratory loosening of bolts. SAE Technical Paper 660432, 1966.

[68] Sakai T. Investigations of bolt loosening mechanisms: 2nd report, on the center bolts of twisted joints. Bull JSME 21(159): 1391-1394 (1978)

[69] Yokoyama T, Olsson M, Izumi S, Sakai S. Investigation into the self-loosening behavior of bolted joint subjected to rotational loading. Eng Fail Anal 23(159): 35-43 (2012)

[70] Fujioka Y. Behavior and mechanisms of bolt self-loosening under transverse load due to vibrations. In ASME 2008 International Mechanical Engineering Congress and Exposition, Boston, Massachusetts, USA, 2008: 27-35.

[71] Haviland G S. A Logical Approach to Secure Bolting and Locking. Newington: Loctite Corporation, 1980.

[72] Haviland G S. Designing with threaded fasteners. Mech Eng 105(10): 17-31 (1983)

[73] Dong Y B, Hess D P. The effect of thread dimensional conformance on vibration-induced loosening. J Vib Acoust 121(2): 209-213 (1999)

[74] Pai N G, Hess D P. Influence of fastener placement on vibration-induced loosening. J Sound Vib 268(3): 617-626 (2003)

[75] Du Y Q, Liu J H, Liu X T, Cai Z B, Peng J F, Zhu M H. Research on self-loosening behavior of bolted joints under eccentric excitation. J Mech Eng 54(14): 74-81 (2018)

[76] Ishimura M, Sawa T, Karami A, Nagao T. Bolt-nut loosening in bolted flange connections under repeated bending moments. In ASME 2010 Pressure Vessels and Piping Division/K-PVP Conference, Bellevue, Washington, USA, 2010: 405-413.

[77] Baubles R C, McCormick G J, Faroni C C. Loosening of Fasteners by Vibration. Union NJ: Elastic Stop Nut Corporation of America (ESNA), 1966.

[78] Faroni C C. Maintaining Tightness of Threaded Fasteners. Union NJ: Amerace Corporation, ESNA Division, 1967.

[79] Koga K. Loosening by repeated impact of threaded fastenings. Bull JSME 13(55): 140-149 (1970).

[80] Koga K. The effect of thread angle on loosening by impact: 1st report, theoretical analysis. Bull JSME 16(96): 1010-1019 (1973)

[81] Kasei S, Matsuoka H. Considerations of thread-loosening by transverse impacts. J Press Vess Technol 367: 117-123 (1998)

[82] Dong Y, Hess D P. Shock-induced loosening of dimensionally non-conforming threaded fasteners. J Sound Vib 231(2): 451-459 (2000)

[83] Daadbin A, Chow Y M. A theoretical model to study thread loosening. Mech Mach Theory 27(1): 69-74 (1992)

[84] Shoji Y, Sawa T. Self-loosening mechanism of nuts due to impacts. In ASME 2008 Pressure Vessels and Piping Conference, Chicago, Illinois, USA, 2008: 219-225.

[85] Jiang Y Y, Zhang M, Park T W, Lee C H. An experimental investigation on self-loosening of bolted joints. In ASME 2003 Pressure Vessel and Piping Conference, Cleveland, $\mathrm{OH}, \mathrm{USA}, 2003$.

[86] Zhang M Y. Research on simulation prediction method of loosening life of bolted joint based on thread wear. Ph.D. Thesis. Chengdu (China): Southwest Jiaotong University, 2019.

[87] Li H J, Tian Y, Meng Y G, Chen K K. Experimental study of the loosening of threaded fasteners with transverse vibration. J Tsinghua Univ (Sci Technol) 56(2): 171-175, 184 (2016)

[88] Wu J, Liao R D, Ding X Y. Research on prediction of lateral loose life of threaded connection structure and its influencing factors. Struct Environ Eng 46(2): 35-41 (2019)

[89] Nishimura N, Hattori T, Yamashita M, Hayakawa N. Sliding and loosening behavior of thread joints under transverse loading. Key Eng Mater 353-358: 894-897 (2007)

[90] Nishimura N, Hattori T, Yamashita M, Hayakawa N. Self loosening behavior of metal thread joints under transverse cyclic loading. Key Eng Mater 340-341: 1467-1472 (2007)

[91] Yamagishi T, Asahina T, Araki D, Sano H, Masuda K, Hattori T. Loosening and sliding behaviour of bolt-nut fastener under transverse loading. Mech Eng J 5(3): 16-00622 (2018)

[92] Hattori T, Yamashita M, Mizuno H, Naruse T. Loosening and sliding behaviour of bolt-nut fastener under transverse loading. EPJ Web Conf 6: 08002 (2010)

[93] Housari B A, Nassar S A. Effect of thread and bearing friction coefficients on the vibration-induced loosening of threaded fasteners. J Vib Acoust 129(4): 484-494 (2007)

[94] Yang X J, Nassar S A. Analytical and experimental investigation of self-loosening of preloaded cap screw fasteners. J Vib Acoust 133: 031007 (2011)

[95] Yang X J, Nassar S A, Wu Z J. Criterion for preventing self-loosening of preloaded cap screws under transverse cyclic excitation. J Vib Acoust 133(4): 041013 (2011)

[96] Zaki A M, Nassar S A, Yang X J. Vibration loosening model for preloaded countersunk-head bolts. In ASME 2010 Pressure Vessels and Piping Division/K-PVP Conference, Bellevue, Washington, USA, 2010: 361-371.

[97] Zaki A M, Nassar S A, Yang X J. Effect of thread and bearing friction coefficients on the self-loosening of preloaded countersunk-head bolts under periodic transverse excitation. J Tribol 132(3): 031601 (2010)

[98] Zaki A M, Nassar S A, Yang X J. Criterion for preventing self-loosening of preloaded countersunk head threaded fasteners. In ASME 2011 Pressure Vessels and Piping Conference, Baltimore, Maryland, USA, 2011: 369-380. 
[99] Sun Q C, Lin Q Y, Yang B, Zhang X L, Wang L T. Mechanism and quantitative evaluation model of slip-induced loosening for bolted joints. Assembly Autom 40(4): 577-588 (2019)

[100] Zhang M Y, Lu L T, Tang M M, Zeng D F. Research on numerical calculation method of critical load for bolt loosening under transverse loading. $J$ Mech Eng 54(5): 173-178 (2018)

[101] Gong H, Liu J H, Ding X Y. Study on the critical loosening condition toward a new design guideline for bolted joints. Proc Inst Mech Eng C: J Mech Eng Sci 233(9): 3302-3316 (2019)

[102] GB/T 10431-2008. Transverse vibration testing method for fasteners. Beijing (China): China Standard Press, 2008.

[103] DIN 65151. Aerospace series-dynamic testing of the locking characteristics of fasteners under transverse loading conditions (vibration test). Berlin (Germany): German Institute for Standardization, 2002.

[104] ISO 16130:2015. Aerospace series-dynamic testing of the locking behaviour of bolted connections under transverse loading conditions (vibration test). Switzerland: International Organization for Standardization (ISO), 2015.

[105] Finkelston R J. How much shake can bolted joints take. Mach Des 44: 122-125 (1972)

[106] Walker R A. The factors which influence the vibration resistance of fasteners. Jenkintown: Standard Pressed Steel Co. (SPS), 1973.

[107] Sanclemente J A, Hess D P. Parametric study of threaded fastener loosening due to cyclic transverse loads. Eng Fail Anal 14(1): 239-249 (2007)

[108] Zhang M, Jiang Y Y, Lee C H. An experimental investigation of the effects of clamped length and loading direction on self-loosening of bolted joints. $J$ Press Vess Technol 128(3): 388-393 (2006)

[109] Marshall M B, Zainal I, Lewis R. Influence of the interfacial pressure distribution on loosening of bolted joints. Strain 47(S2): 65-78 (2011)

[110] Noda N A, Chen X, Sano Y, Wahab M A, Maruyama H, Fujisawa R, Takase Y. Effect of pitch difference between the bolt-nut connections upon the anti-loosening performance and fatigue life. Mater Des 96: 476-489 (2016)

[111] Fukuoka T, Nomura M. Proposition of helical thread modeling with accurate geometry and finite element analysis. J Press Vess Technol 130: 011204 (2008)

[112] Zhu L B, Hong J, Yang G Q, Li B, Yang Z. The slippage analysis at bearing surface of bolted joints due to cyclic transverse loads. In ASME 2012 International Mechanical Engineering Congress and Exposition, Houston, Texas, USA, 2012: 685-690.
[113] Wang W, Xu H, Ma Y, Liu X W, Xu X D. The effect of thread pitch and clearance on self-loosening of bolted joints. J Air Force Eng Univ (Nat Sci Ed) 15(1): 87-90 (2014)

[114] Wang W, Xu H, Ma Y, Liu H P. Self-loosening mechanism of bolted joints under vibration. J Vib Shock 33(22): 198-202 (2014)

[115] Hou S Y, Liao R D. Numerical simulation of self-loosening of bolted joints under cyclic transverse loads. Appl Mech Mater 487: 488-493 (2014)

[116] Xu H L, Yang L H, Yu L. Self-loosening analysis of bolted joints. In 2016 International Conference on Mechanics Design, Manufacturing and Automation, Istanbul, Turkey, 2016.

[117] Liu G W, Wang L J, Jia S L, Yang R. Self-loosening process simulation of bolted joints in $12 \mathrm{kv}$ vacuum circuit breakers under vibration. In 2017 4th International Conference on Electric Power Equipment-Switching Technology, Xi'an, China, 2017: 668-672.

[118] Sawa T, Ishimura M. A bolt-nut loosening mechanism in bolted connections under repeated transverse loadings (effect of inclined bearing surfaces on the loosening). In ASME 2010 Pressure Vessels \& Piping Division / K-PVP Conference, Bellevue, Washington, USA, 2010: 397-403.

[119] Nassar S A, Housari B A. Study of the effect of hole clearance and thread fit on the self-loosening of threaded fasteners. J Mech Des 129: 586-594 (2007)

[120] Yang X J, Nassar S A. Effect of non-parallel wedged surface contact on loosening performance of preloaded bolts under transverse excitation. In ASME 2011 Pressure Vessels and Piping Conference, Baltimore, Maryland, USA, 2011: 405-415.

[121] Yang X J, Nassar S A. Effect of thread profile angle and geometry clearance on the loosening performance of a preloaded bolt-nut system under harmonic transverse excitation. In ASME 2011 Pressure Vessels and Piping Conference, Baltimore, Maryland, USA, 2011: 393-404.

[122] Chen J H, Hsieh S C, Lee A C. The failure of threaded fasteners due to vibration. Proc Inst Mech Eng C: J Mech Eng Sci 219(3): 299-314 (2005)

[123] Fernando S. Mechanisms and prevention of vibration loosening in bolted joints. Aust J Mech Eng 2(2): 73-92 (2005)

[124] Fort V, Bouzid A H, Gratton M. Analytical modeling of self-loosening of bolted joints subjected to transverse loading. J Tribol 141(3): 031205 (2019)

[125] Dorn M, Habrová K, Koubek R, Serrano E. Determination of coefficients of friction for laminated veneer lumber on steel under high pressure loads. Friction 9(2): 367-379 (2021) 


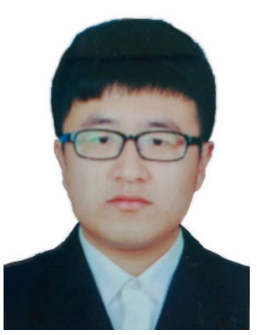

Hao GONG. He received his bachelor degree in mechanical engineering in 2014 from Beijing Institute of Technology, Beijing, China. After then, he was a Ph.D. student in the Digital Manufacturing

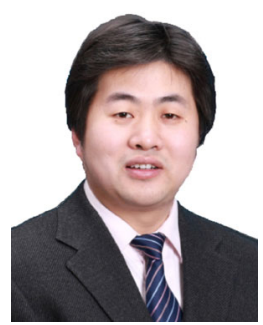

Jianhua LIU. He received his M.S. degree in mechanical engineering in 2002 from Chongqing University, Chongqing, China and received his Ph.D. degree in the same major in 2005 from Beijing Institute of
Laboratory at the same university. He obtained his Ph.D. degree in mechanical engineering in March 2020 and now he is a postdoctor at Beijing Institute of Technology. His research interests include highperformance assembly and high-reliability assembly for threaded fasteners

Technology, Beijing, China. After then, He joined the Digital Manufacturing Laboratory at Beijing Institute of Technology. His current position is a professor and vice president of Graduate School. His research areas cover digital manufacturing, precision assembly and measurement. 